\title{
Expanding the Treatment Landscape for Lennox-Gastaut Syndrome: Current and Future Strategies
}

\author{
Adam Strzelczyk $^{1,2}$ - Susanne Schubert-Bast ${ }^{1,2,3}$ (D)
}

Accepted: 12 December 2020 / Published online: 21 January 2021

(c) The Author(s) 2021

\begin{abstract}
Lennox-Gastaut syndrome (LGS), a childhood-onset severe developmental and epileptic encephalopathy (DEE), is an entity that encompasses a heterogenous group of aetiologies, with no single genetic cause. It is characterised by multiple seizure types, an abnormal EEG with generalised slow spike and wave discharges and cognitive impairment, associated with high morbidity and profound effects on the quality of life of patients and their families. Drug-refractory seizures are a hallmark and treatment is further complicated by its multiple morbidities, which evolve over the patient's lifetime. This review provides a comprehensive overview of the current and future options for the treatment of seizures associated with LGS. Six treatments are specifically indicated as adjunct therapies for the treatment of seizures associated with LGS in the US: lamotrigine, clobazam, rufinamide, topiramate, felbamate and most recently cannabidiol. These therapies have demonstrated reductions in drop seizures in 15\%-68\% of patients across trials, with responder rates ( $\geq 50 \%$ reduction in drop seizures) of $37 \%-78 \%$. Valproate is still the preferred first-line treatment, generally in combination with lamotrigine or clobazam. Other treatments frequently used off-label include the broad spectrum anti-epileptic drugs (AED) levetiracetam, zonisamide and perampanel, while recent evidence from observational studies has indicated that a newer AED, the levetiracetam analogue brivaracetam, may be effective and well tolerated in LGS patients. Other treatments in clinical development include fenfluramine in late phase III, perampanel, soticlestat-OV953/TAK-953, carisbamate and ganaxolone. Non-pharmacologic interventions include the ketogenic diet, vagus nerve stimulation and surgical interventions; these are also expanding, with the potential for less invasive techniques for corpus callosotomy that have promise for reducing complications. However, despite these advancements, patients continue to experience a significant burden. Because LGS is not a single entity, tailoring of treatment is needed as opposed to a 'one size fits all' approach. Further research is needed into the underlying aetiologies and pathophysiology of LGS, together with advancements in treatments that encompass the spectrum of seizures associated with this complex syndrome.
\end{abstract}

\section{Introduction}

Lennox-Gastaut syndrome (LGS) is a childhood-onset severe developmental and epileptic encephalopathy (DEE), associated with high morbidity and profound effects on the quality of life (QoL) of patients and their families [1, 2].

Adam Strzelczyk

strzelczyk@med.uni-frankfurt.de

1 Epilepsy Center Frankfurt Rhine-Main, Center of Neurology and Neurosurgery, Goethe-University Frankfurt,

Schleusenweg 2-16 (Haus 95), 60528 Frankfurt am Main, Germany

2 LOEWE Center for Personalized and Translational Epilepsy Research (CePTER), Goethe-University Frankfurt, Frankfurt am Main, Germany

3 Department of Neuropediatrics, Goethe-University Frankfurt, Frankfurt am Main, Germany
LGS is a rare disease; it has an estimated incidence rate of 0.1 to 0.28 per 100,000 overall, with an incidence rate of 2 per 100,000 in children, accounting for approximately $2-5 \%$ of all childhood epilepsies, with a slight male preponderance [3].

The onset of LGS typically occurs by 12 years of age, with a peak between 3 and 5 years [1]; late-onset cases have been reported, albeit rarely [4]. A universally agreed-upon definition of LGS does not yet exist, and it has a wide variety of clinical presentations that continue to change and evolve over time $[2,5,6]$. However, it is traditionally defined as having a 'triad' of features encompassing (i) epilepsy with multiple pharmaco-resistant seizure semiologies, (ii) a generalised spike wave discharge pattern on EEG (Fig. 1) and (iii) cognitive and behavioural impairments (Fig. 2) [1, 2, 5, 6]. Tonic seizures are a hallmark of LGS, while other common seizure types include atypical absences and tonic or 


\section{Key Points}

Lennox-Gastaut syndrome (LGS) is a complex syndrome that is challenging to treat.

LGS is an entity with a range of underlying causes that is characterised by multiple seizure types that are drugrefractory (with tonic seizures being a hallmark feature), an abnormal EEG with generalised slow spike and wave discharges and cognitive impairment.

There are a range of pharmacological and non-pharmacological options for the treatment of seizures associated with LGS, which differ regarding mechanism of action, safety and tolerability.

Valproate in combination with the licensed pharmacotherapies lamotrigine or clobazam are a mainstay of treatment; other licensed adjunct therapies include rufinamide, topiramate, felbamate and most recently cannabidiol.

A personalised approach, tailored to the individual symptoms and responses of the patient during all stages of care, with regular assessment of treatment options, is particularly important for LGS.

atonic drop attacks; other less common types include clonic, myoclonic and generalised tonic-clonic seizures. The characteristic EEG abnormalities include interictal slow spike waves at $<3 \mathrm{~Hz}$, occurring while awake, typically in series and often evolving into subclinical seizure patterns, and paroxysmal fast rhythms (10-20 Hz) during sleep (Fig. 1) [2, 6]. Most patients with LGS experience progressive cognitive impairment, marked by developmental delay, intellectual

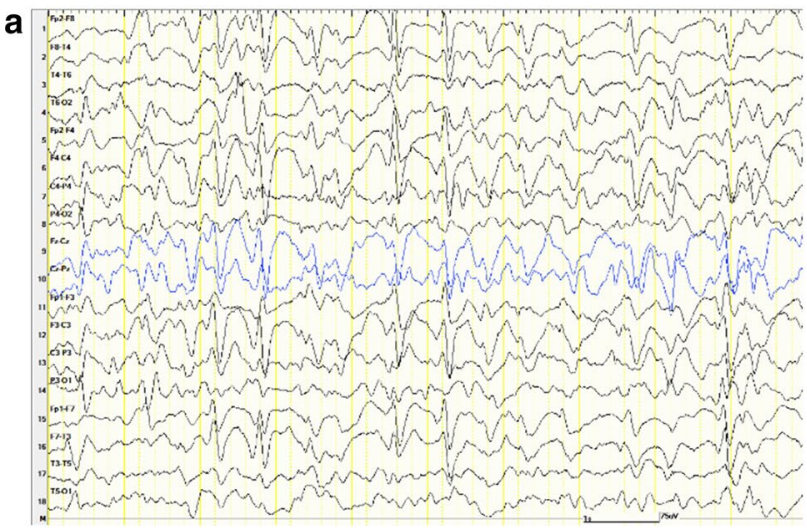

disability and other behavioural problems such as hyperactivity, aggression and autistic behaviours $[2,6]$.

Early and accurate diagnosis is crucial for effective management $[5,6]$, which is especially important given the compelling data in other DEEs that early treatment is associated with improved outcomes [7]. However, early diagnosis is significantly hampered by a number of challenges including a lack of agreed-upon clinical criteria and assessment measures, absence of specific biological markers and the diverse and evolving manifestations of the syndrome, which may have overlapping clinical features with other DEEs (Fig. 2) $[2,5,6]$. With regard to the latter points, it can take time for the characteristic symptoms to appear-often a year or more. Furthermore, because tonic seizures can be absent at the initial stages, differential diagnosis from other DEEs may be difficult, especially with epilepsies with myoclonicatonic/astatic seizures. An additional impediment to early diagnosis is that there is no single underlying cause of LGS, and indeed in $25-33 \%$ of cases the cause is unknown. The known aetiologies are varied and include the result of a brain abnormality (an ischaemic or haemorrhagic stroke, developmental malformation [e.g. cortical dysplasia], congenital infections, central nervous system [CNS] infections [e.g. meningitis], or tumours) and development from other severe infantile encephalopathies such as West syndrome (infantile spasms) (Fig. 2) [2, 8]. In addition, more rarely, LGS may be associated with the rare genetic disorder tuberous sclerosis complex (TSC), hereditary metabolic disorders, as well as other genetic disorders, with possible, albeit poorly defined, relationships with Down's syndrome and Miller-Dieker syndrome (Fig. 2) [2, 8, 9]. Indeed, LGS may represent the endstage of various epilepsies.

LGS imposes a substantial burden on people living with the condition and their families [10-12]. Atonic seizures are common in LGS; they are also known as 'drop attacks' or 'drop seizures' because they are characterised by a sudden

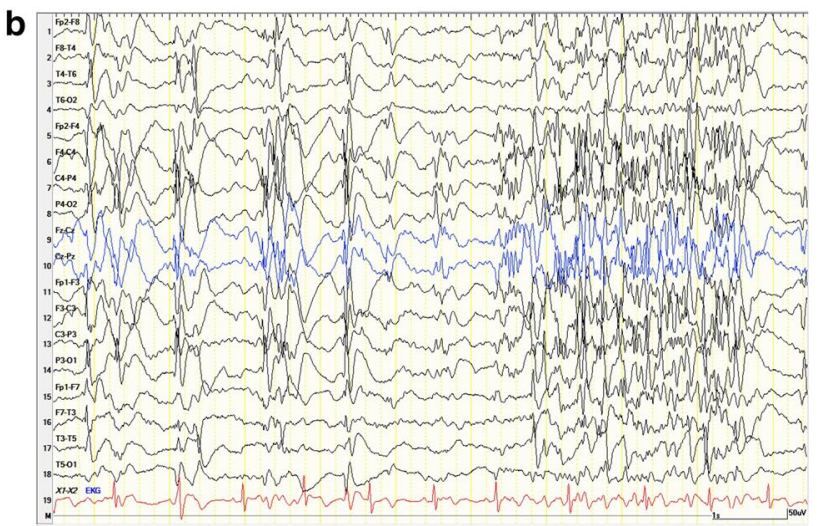

Figure 1 Typical EEG patterns in Lennox-Gastaut syndrome (LGS): a bilateral 1.5-2/second slow spike waves, and b bilateral high frequent rhythms $16-20 / \mathrm{s}$ in NREM sleep. EEG electroencephalogram, NREM non-rapid eye movement 

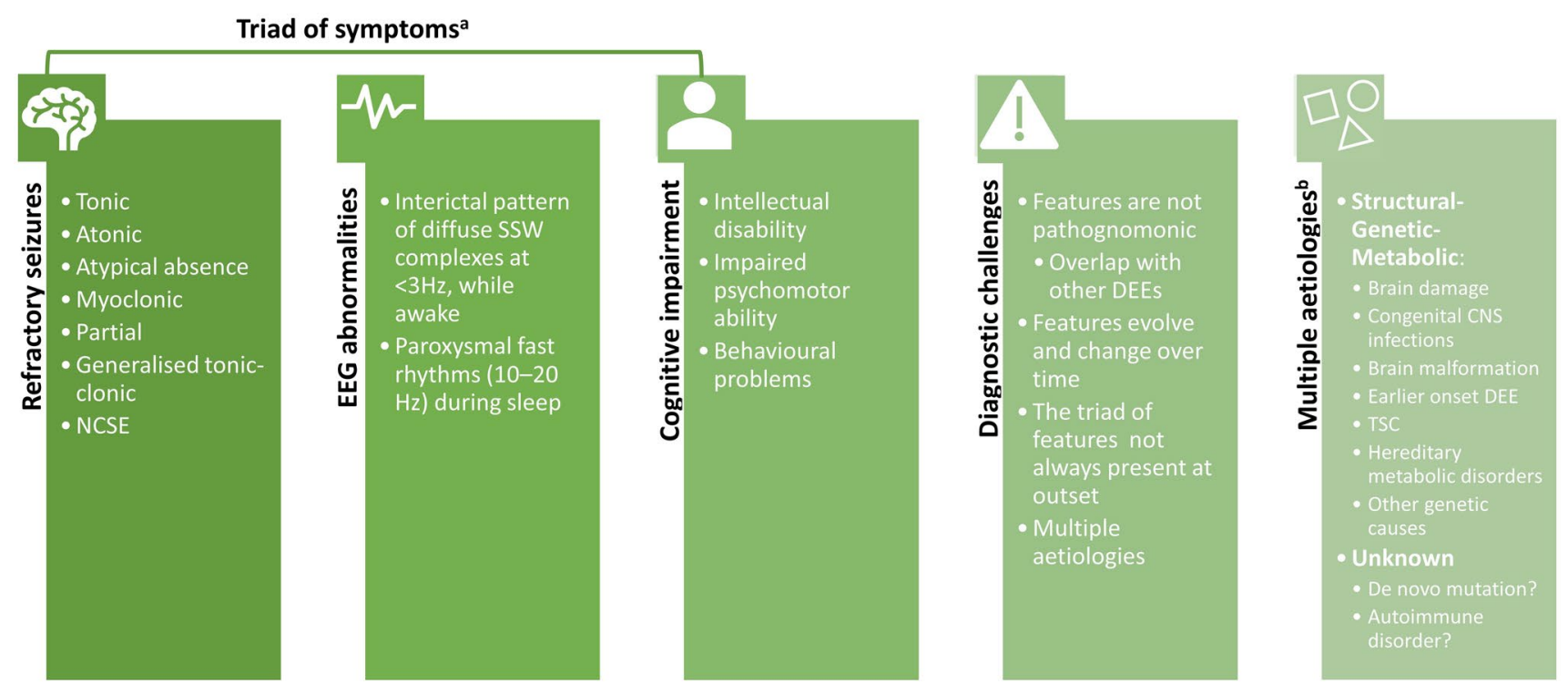

Figure 2 Triad of symptoms characteristic of Lennox-Gastaut syndrome (LGS), diagnostic challenges and aetiology. ${ }^{\mathrm{a}}$ The characteristic LGS EEG pattern with slow SSW (Fig. 1) is a key diagnostic criteria. In contrast, cognitive impairment (intellectual disability and associated behavioural problems) is not always present at the outset of LGS and therefore this part of the 'triad' is not always included in

loss of muscle tone that can result in the patient falling to the ground. Because of the risks of injuries, control of atonic seizures is an important outcome of treatment [3]. Between 50 and $75 \%$ of patients with LGS are also likely to have at least one episode of non-convulsive status epilepticus in their history [5], and this concerning feature is a major contributor to the increased mortality rates [13]. Most adults with LGS are unable to live independently due to their intellectual disability, together with seizures that usually continue into adulthood [14-17]. The burden of care for families can take its toll on physical, mental, and emotional health [12]. In addition, LGS is associated with substantial economic consequences, with high healthcare utilisation and costs [18-21].

Given the complex nature of the syndrome, with its highly drug-resistant seizures, the treatment of LGS is challenging [1, 5, 22-25], necessitating novel effective and tolerable treatments that reduce seizures and improve QoL. This review summarises the current and future options for the treatment of seizures associated with LGS (Fig. 3), including the six treatments that are specifically indicated for the treatment of seizures associated with LGS in the US (lamotrigine, clobazam, rufinamide, cannabidiol, topiramate and felbamate) (Table 1), as well as other options that are frequently used off-label. In particular, we focus on recent clinical evidence for rufinamide, a third-generation antiseizure treatment licensed for LGS, cannabidiol, a newly approved treatment for LGS, and fenfluramine, an upcoming treatment the diagnostic criteria. ${ }^{\mathbf{b}}$ Brain damage can be the result of hypoxia at birth or head injuries, among others. DEEs developmental and epileptic encephalopathies, EEG electroencephalogram, NCSE non-convulsive status epilepticus, $S S W$ slow spike wave, $T S C$ tuberous sclerosis complex

currently in phase III clinical development. Other treatments in clinical development including perampanel, soticlestat-OV953/TAK-953, carisbamate and ganaxolone are also discussed. The review also covers non-pharmacological agents including the ketogenic diet, vagus nerve stimulation and surgical interventions, including progress in developing minimally invasive strategies for corpus callosotomy.

\section{Pharmacologic Agents}

\subsection{Conventional Antiepileptic Drugs Widely Used for Lennox-Gastaut Syndrome (LGS) and Steroids}

\subsubsection{Valproate}

Valproate was first discovered in the 1960s [26] as a broadspectrum antiepileptic drug (AED), effective against seizures of both focal and generalised onset. Despite the age of this drug, it is generally still the preferred first-line therapy for people presenting with epilepsy involving generalised or multiple seizure types, including in patients with LGS $[2,27]$ (Fig. 3). As with many AEDs, it is thought to exert its anticonvulsant activity via several mechanisms. These include inhibition of neuronal voltage-gated sodium channels, blockage of T-type calcium channels, and enhanced neurotransmitter synthesis or release to alter GABA turnover 



Fig. 3 Current and future treatment of Lennox-Gastaut syndrome (LGS). Adapted from Cross et al. [2] and Crespel et al. [1]. 'Licensed in the US; see Table 1 for approvals in the EU; not all therapies are available in all countries/regions. ${ }^{\text {b}}$ The decision should be individualised and consider different disease symptoms, treatment toxicity profiles, previous treatment, caregiver/patient preferences and country availability. ${ }^{\mathrm{c}}$ Limited evidence, based on cohort studies. ${ }^{\mathrm{d}}$ In care-

[28]. Though it is not specifically licensed for LGS, one uncontrolled, observational study involving 336 total patients with epilepsy, 38 of whom had LGS, showed that $21 \%$ of the LGS patients experienced total seizure control on valproate [29]. Another 55\% showed a $\geq 50 \%$ improvement in seizure frequency, while only mild adverse events (AEs) were reported. Valproate proved particularly effective against drop attacks, atypical absences and myoclonic seizures, similar to what was reported in a separate study in patients with epilepsy [30]. Safety considerations to be aware of and notable drug-drug interactions are shown in Table 1; of note, valproate can result in hepatotoxicity and pancreatitis, resulting in a black box warning in the US label, and due to its teratogenicity, contraception must be ensured in females of childbearing potential [23, 24, 31]. However, overall, valproate is the mainstay treatment in the first-line setting (Fig. 3), underpinned by an abundance of physician experience, cost effectiveness and it's positive mood-stabilising effects [17].

\subsubsection{Clobazam}

Clobazam, a 1,5-benzodiazepine compound that has a better safety and tolerability profile compared with other benzodiazepines [32], acts by binding to postsynaptic fully selected patients. ${ }^{\text {e}}$ Last line due to risk of fatal aplastic anaemia and hepatic failure; limited availability (not approved by the European Medicines Agency). $B R V$ brivaracetam, $C B D$ cannabidiol, $C L B$ clobazam, FFA fenfluramine, FLB felbamate, KD ketogenic diet, $L E V$ levetiracetam, $L T G$ lamotrigine, $P E R$ perampanel, $R U F$ rufinamide, $T P M$ topiramate, $V N S$ vagus nerve stimulation, $V P A$ valproate, $Z N S$ zonisamide

GABA receptors to increase the action potential threshold and reduce the frequency of action potentials, therefore decreasing the likelihood of seizures [24]. Although clobazam has been available as an AED for decades, it has only recently been approved in the US specifically for LGS, while it is approved as adjunctive therapy in epilepsy in the European Union (EU) (Table 1). After a phase II clinical trial showed that clobazam was well tolerated and reduced the weekly rates of drop and non-drop seizures in LGS patients [33], a phase III, double-blind, placebo-controlled, multicentre clinical trial was conducted to further evaluate the safety and efficacy of clobazam to treat LGS [34]. During this trial, patients were given a low $(0.25 \mathrm{mg} /$ $\mathrm{kg}$ /day), medium ( $0.5 \mathrm{mg} / \mathrm{kg} /$ day $)$, or high $(1 \mathrm{mg} / \mathrm{kg} /$ day $)$ dose of clobazam for 12 weeks, with the option to continue treatment after this point. The average weekly rate of total seizures and drop seizures alone decreased in a dosedependent manner, while responder rates increased with the dosage (Table 2; Fig. 4). Along with these promising results, all clobazam dosages resulted in an improvement of symptoms according to physicians' and caregivers' global evaluations (Table 2). There were no new safety signals during this trial, though nine developed pneumonia as a serious AE (SAE). Following these promising results, 267 of the patients involved in the phase II and phase III 
Table 1 Summary of pharmacotherapies widely used, licensed or upcoming for Lennox-Gastaut syndrome (LGS)

\begin{tabular}{|c|c|c|c|c|c|c|c|c|c|}
\hline & \multicolumn{2}{|c|}{$\begin{array}{l}\text { Indication } \\
\text { for LGS }\end{array}$} & \multicolumn{2}{|c|}{$\begin{array}{c}\text { Indication } \\
\text { for } \\
\text { seizures }^{a}\end{array}$} & \multirow[t]{2}{*}{ Safety considerations } & \multirow{2}{*}{\multicolumn{4}{|c|}{ Key drug-drug interactions with other AEDs }} \\
\hline & US & EU & US & EU & & & & & \\
\hline VPA & $\mathrm{x}$ & $x$ & $\checkmark$ & $\checkmark$ & $\begin{array}{l}\text { - Warning for hepatotoxicity, teratogenicity and } \\
\text { pancreatitis (Boxed Warning in US label): } \\
\quad \quad \text { Contraception must be ensured due to } \\
\text { teratogenic effect }\end{array}$ & $\begin{array}{l}\text { VPA increases } \\
\text { LTG levels (see } \\
\text { LTG below) }\end{array}$ & $\begin{array}{l}\text { VPA } \\
\text { RUF } \\
\text { RUF }\end{array}$ & $\begin{array}{l}\text { increases } \\
\text { levels (see } \\
\text { below) }\end{array}$ & $\begin{array}{l}\text { Concomitant use } \\
\text { of VPA with CBD } \\
\text { increases the } \\
\text { risk of } \\
\text { transaminase } \\
\text { elevations (see } \\
\text { CBD below) }\end{array}$ \\
\hline LTG & $\checkmark$ & $\checkmark$ & $\checkmark$ & $\mathrm{x}$ & $\begin{array}{l}\text { Rare AE: life-threatening serious rash and/or rash- } \\
\text { related death may result (Boxed Warning in US label) } \\
\text { Risk can be reduced by the mandatory slow } \\
\text { titration of LTG }\end{array}$ & $\begin{array}{l}\text { - VPA increases L } \\
\circ \quad \text { Dose reducti } \\
\circ \quad \text { Very slow tit }\end{array}$ & $\begin{array}{l}\text { G concentr } \\
n \text { of LTG } r \\
\text { tion of LTC }\end{array}$ & $\begin{array}{l}\text { ations more } \\
\text { equired } \\
3 \text { required wit }\end{array}$ & Ian 2-fold. \\
\hline CLB & $\checkmark$ & $x$ & $\mathrm{x}$ & $\checkmark$ & $\begin{array}{l}\text { Concomitant use of benzodiazepines and opioids may } \\
\text { result in profound sedation, respiratory depression, } \\
\text { coma, and death (Boxed Warning) } \\
\text { Risk of physical and psychological dependence }\end{array}$ & $\begin{array}{l}\text { - } \quad \text { CLB interacts wit } \\
\circ \quad \text { Potential inc } \\
\text { sedation req }\end{array}$ & $\begin{array}{l}\text { CBD } \\
\text { ases in the } \\
\text { ring dose }\end{array}$ & $\begin{array}{l}\text { incidence o } \\
\text { eduction of } C\end{array}$ & $\begin{array}{l}\text { somnolence and } \\
\text { LB }\end{array}$ \\
\hline RUF & $\checkmark$ & $\checkmark$ & $x$ & $x$ & & $\begin{array}{ll}\text { - } & \text { VPA increases R } \\
& \circ \quad \text { Dose reduct }\end{array}$ & $\begin{array}{l}\text { F concentr } \\
n \text { of RUF } n\end{array}$ & $\begin{array}{l}\text { rations } \\
\text { nay be requir }\end{array}$ & \\
\hline $\mathrm{CBD}^{\mathrm{b}}$ & $\checkmark$ & $\checkmark$ & $\checkmark$ & $\checkmark$ & $\begin{array}{l}\text { - Concomitant use of VPA and higher doses of CBD } \\
\text { increase the risk of transaminase elevations. }\end{array}$ & $\begin{array}{l}\text { - } \mathrm{CBD} \text { and/or VPA } \\
\text { reduced or discor } \\
\text { clinically significa } \\
\text { increases of tran } \\
\text { occur }\end{array}$ & $\begin{array}{l}\text { hould be } \\
\text { inued if } \\
\text { aminases }\end{array}$ & $\begin{array}{l}\text { Bi-dire } \\
\text { occur v } \\
0 \quad \text { en } \\
\text { ph } \\
\text { an } \\
\text { dri } \\
\text { Potenti } \\
\text { inciden } \\
\text { sedatio } \\
\text { reducti }\end{array}$ & $\begin{array}{l}\text { tional PK interactions } \\
\text { ith CLB: } \\
\text { lanced } \\
\text { inmacological effects } \\
\text { ncrease in adverse } \\
g \text { reactions } \\
\text { l increases in the } \\
\text { ie of somnolence and } \\
\text { requiring dose } \\
n \text { of CLB }\end{array}$ \\
\hline TPM & $\checkmark$ & $\checkmark$ & $\checkmark$ & $\checkmark$ & $\begin{array}{l}\text { - Increased risks of: } \\
\circ \quad \text { Hyperammonaemia, especially in combination with } \\
\text { VPA } \\
\circ \quad \text { Cognitive side effects } \\
\circ \quad \text { Speech problems }\end{array}$ & $\begin{array}{l}\text { - TPM + VPA asso } \\
\text { with and without } \\
\text { Examine blo } \\
\text { of hypotherm }\end{array}$ & $\begin{array}{l}\text { iated with } \\
\text { ceephalope } \\
d \text { ammonia } \\
\text { a has been }\end{array}$ & $\begin{array}{l}\text { nypothermia } \\
\text { athy. } \\
\text { levels in pat } \\
\text { reported }\end{array}$ & $\begin{array}{l}\text { nd hyperammonemia } \\
\text { ents in whom the onset }\end{array}$ \\
\hline $\mathrm{FFA}^{\mathrm{c}, \mathrm{d}}$ & $x$ & $x$ & $\checkmark$ & - & $\begin{array}{l}\text { Warning for valvular heart disease and pulmonary } \\
\text { arterial hypertension; echocardiogram assessments are } \\
\text { required before, during, and after treatment (Boxed } \\
\text { warning in US label) }\end{array}$ & $\begin{array}{l}\text { FFA + STP + CLI } \\
\text { decreases its me } \\
0 \quad \text { Max daily do }\end{array}$ & $\begin{array}{l}\text { increases } \\
\text { abolite, nor } \\
\text { age of } 0.2\end{array}$ & $\begin{array}{l}\text { FFA plasma } \\
\text { fenfluramine } \\
\mathrm{mg} / \mathrm{kg} \text { twice }\end{array}$ & $\begin{array}{l}\text { oncentrations and } \\
\text { aily }\end{array}$ \\
\hline FLB & $\checkmark$ & $x$ & $\checkmark$ & $x$ & $\begin{array}{l}\text { Warnings for fatal aplastic anaemia and hepatic failure; } \\
\text { should not be used until there has been a complete } \\
\text { discussion of the risks and written informed consent is } \\
\text { given }\end{array}$ & - & & & \\
\hline
\end{tabular}

The colours correspond to the colours used for the equivalent pharmacotherapies in Fig. 4

${ }^{\mathrm{a}}$ Associated with epilepsy and/or other DEEs

${ }^{\mathrm{b}}$ Approved for the treatment of seizures associated with DS, LGS and TSC in patients aged $\geq 1$ year

${ }^{\mathrm{c}}$ Approved for the treatment of seizures associated with DS in patients aged $\geq 2$ years in the US and in the EU

${ }^{\mathrm{d}}$ In phase III development for LGS

$A E$ adverse event, $A E D$ antiepileptic drug, $C B D$ cannabidiol, $C L B$ clobazam, DEEs developmental and epileptic encephalopathies, DS Dravet syndrome, FFA fenfluramine, FLB felbamate, $L T G$ lamotrigine, $P K$ pharmacokinetic, $R U F$ rufinamide, STP stiripentol, TPM topiramate, TSC tuberous sclerosis complex, $V P A$ valproate

trials continued adjunctive treatment with clobazam in a multicentre, open-label extension (OLE) study [35]. Over the course of 2-6 years, $16 \%$ of patients showed seizure control with clobazam monotherapy, while the decrease in the weekly rate of total seizures and drop seizures alone was maintained to year 5 in $85 \%$ and $85-91 \%$ of patients, respectively. The percentage of responders to clobazam was consistent with the original trials, and there was no indication of tolerance as the mean modal clobazam dose did not increase with time. After year 3 of the study, $80 \%$ of patients' caregivers considered symptoms "very much improved" or "much improved", suggesting a considerable improvement in QoL. Although 60\% of patients experienced an $\mathrm{AE}$, most were mild or moderate, with only $5 \%$ of patients reporting treatment-related SAEs. One patient had a convulsion with a fatal outcome during this study that was considered by the investigator as "possibly related" to clobazam treatment. Overall, clobazam showed an ability to elicit seizure freedom or improvement in patients treated over several years. However, some studies have shown that approximately one-third of patients may develop tolerance, while both cognitive and behavioural AEs have been associated with the drug $[2,24,36]$. In addition, physical and/ or psychic dependence may develop, especially during prolonged use (Table 1). Despite these issues, clobazam is a useful combination therapy, with few reported harmful drug-drug interactions (Table 2), and it is considered a first-line treatment option (Fig. 3). 


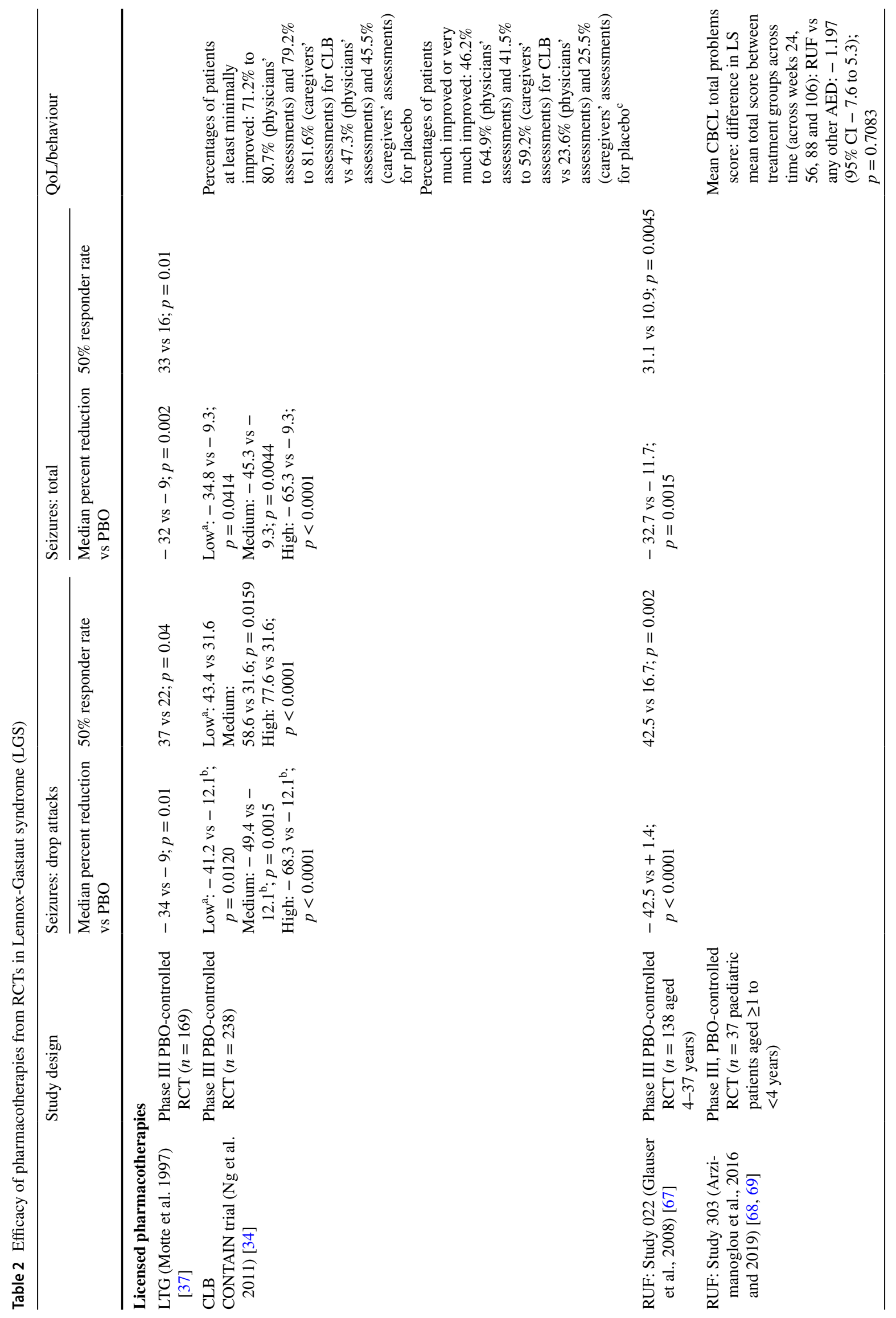




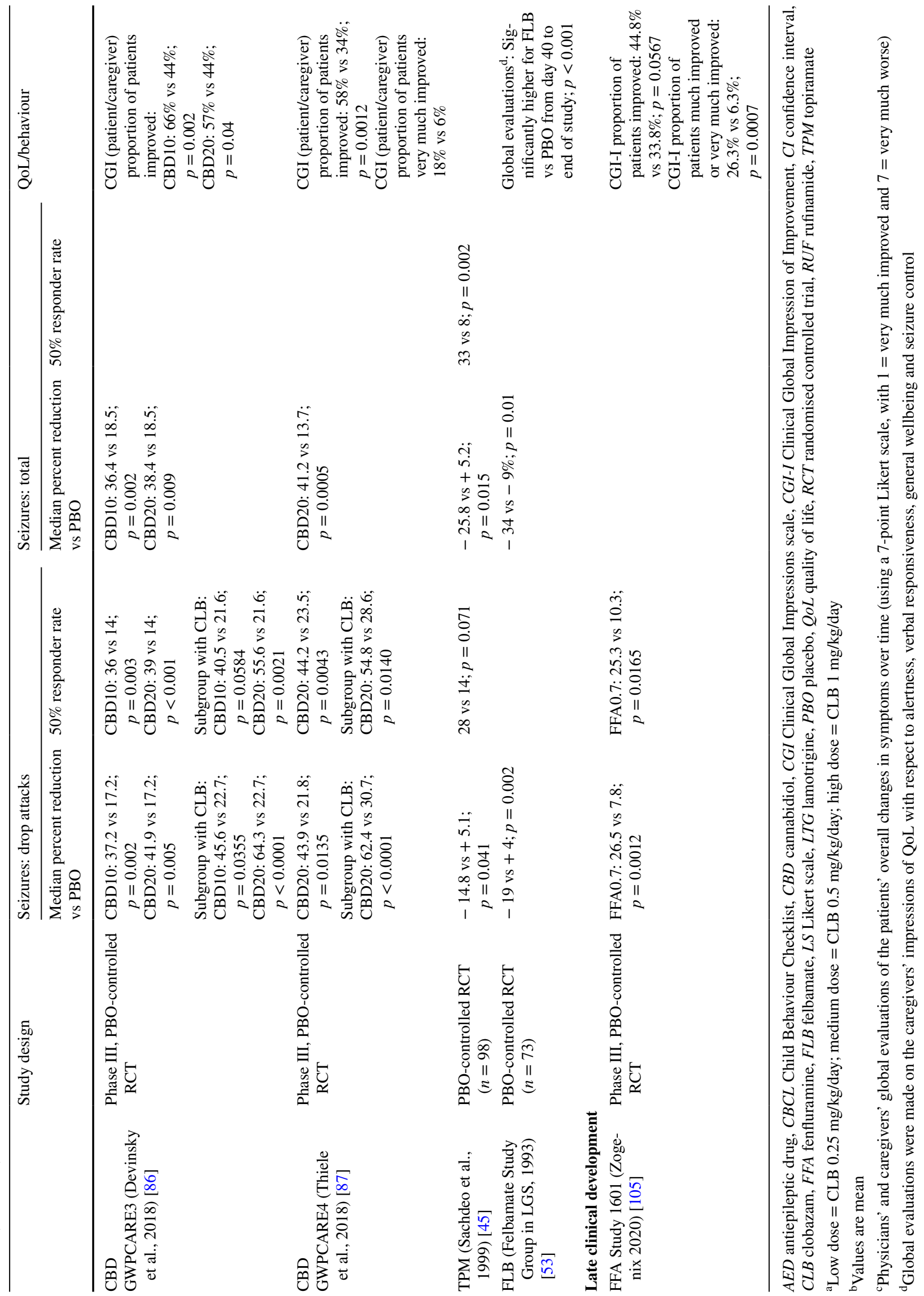



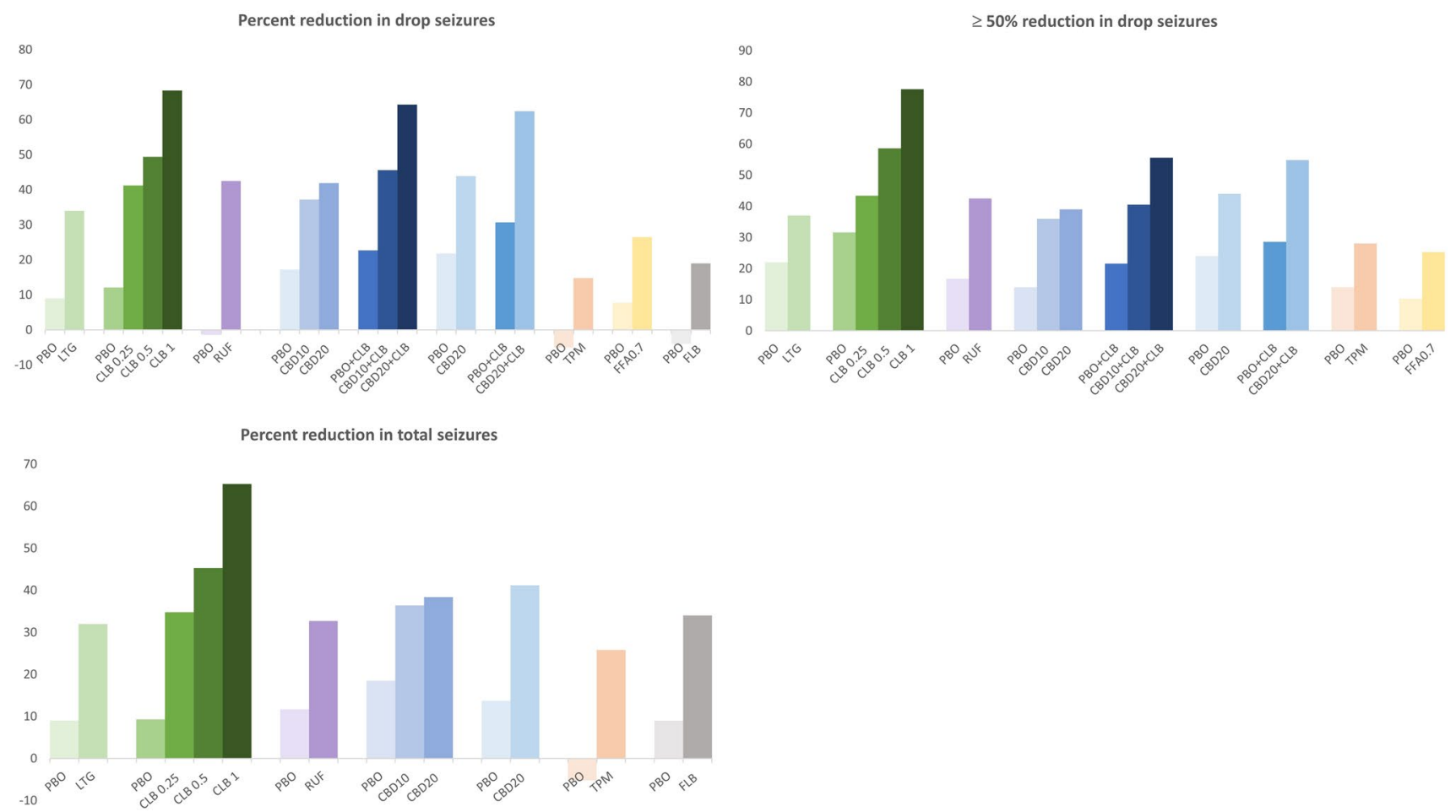

Figure 4 Seizure efficacy of pharmacotherapies from RCTs in Lennox-Gastaut syndrome (LGS). $C B D$ cannabidiol, $C L B$ clobazam, $F F A$ fenfluramine, $F L B$ felbamate, $L T G$ lamotrigine, $P B O$ placebo, $R C T$ randomised controlled trial, $R U F$ rufinamide, $T P M$ topiramate

\subsection{Second-Generation Antiseizure Treatment Licensed for LGS}

\subsubsection{Lamotrigine}

Lamotrigine's mechanism of action is not fully understood; however, it is thought that the drug selectively stabilises voltage-sensitive sodium channels, inhibiting the release of excitatory neurotransmitters $[37,38]$. It is possible that lamotrigine acts to reduce the number of spike-and-wave events that are typical of LGS $[39,40]$, and the drug has been shown to be effective at treating refractory epilepsy when used as an adjunctive therapy [41]. These early findings prompted a double-blind, placebo-controlled, randomised controlled trial (RCT) to determine the efficacy of lamotrigine against LGS, involving 169 patients, which led to the approval of lamotrigine specifically for LGS in the US and EU [37]. The lamotrigine-treated group were titrated up to $100-200 \mathrm{mg} /$ day if on concomitant valproate or $300-400 \mathrm{mg} /$ day if not, resulting in a $32 \%$ median reduction in all major seizures, compared with just $9 \%$ in the placebo group (Table 2; Fig. 4). Similar results were seen with tonic-clonic seizure or drop attack frequency alone (Table 2; Fig. 4). Of note, valproate increases lamotrigine concentrations more than two-fold, and there have also been suggestions that these two therapies may work synergistically to provide enhanced seizure control over each drug independently [42].

The most common AEs of lamotrigine seen in the study were pharyngitis and fever, common childhood ailments, and only three patients prematurely discontinued treatment due to AEs. However, lamotrigine is associated with the development of rash, common particularly in younger patients [31], which can progress, albeit rarely, into the serious and occasionally fatal Stevens-Johnson syndrome (Table 1) [43]. This risk can be reduced by the mandatory slow titration of lamotrigine (combination therapy starting dosage $0.3 \mathrm{mg} / \mathrm{kg} /$ day), which is even slower with valproate (starting dosage $0.15 \mathrm{mg} / \mathrm{kg} /$ day) due to the enzyme inhibition of valproate and consequent increase in lamotrigine levels (Table 1). With these precautions, lamotrigine in combination with valproate remains a mainstay of treatment (Fig. 3).

\subsubsection{Topiramate}

Topiramate, a fructose derivative, is a broad-spectrum AED able to prevent the onset of multiple seizure types [44]. Topiramate is specifically approved for use in LGS patients (Table 1). Though it is not known which of its mechanisms of action is most important for its anticonvulsant effects, 
topiramate is known to modulate voltage-gated sodium channels, reduce neuronal excitation by mediating $N$-methylD-aspartate receptors, enhance inhibition of GABA-mediated neurotransmission, inhibit carbonic anhydrase, and modulate voltage-gated calcium channels [27, 44].

The efficacy of topiramate as an adjunctive therapy in LGS patients has been demonstrated in a double-blind, placebo-controlled RCT involving 98 patients (Table 2; Fig. 4) [45]. Patients were given up to $6 \mathrm{mg} / \mathrm{kg} /$ day (titrated up from $1 \mathrm{mg} / \mathrm{kg} /$ day) of topiramate for 11 weeks, while seizure frequency and severity were monitored. topiramate significantly reduced the average monthly rate of both drop attacks (defined as tonic and atonic seizures in this study) and major motor seizures by $14.8 \%$ and $25.8 \%$, respectively, compared with a $5.1 \%$ and $5.2 \%$ increase in drop attacks and major motor seizures in the placebo-treated group (Table 2; Fig. 4). Importantly, there was a $\geq 50 \%$ reduction in major motor seizure frequency from baseline frequency in onethird of topiramate-treated patients, compared with just $8 \%$ of the placebo-treated patients (Table 2; Fig. 4). Along with the reduction in frequency, topiramate also reduced seizure severity, with topiramate-treated patients approximately twice as likely to show an improvement, while one patient became seizure free. The AEs reported during this trial were mostly mild or moderate; however, 23 patients on topiramate experienced severe AEs that were most often CNSrelated. Overall, this trial demonstrated topiramate to be a well-tolerated add-on treatment for LGS and the results of this study have since been mirrored in open-label studies, showing long-term reduction in seizure frequency in patients with LGS [46, 47]. The American Academy of Neurology (AAN) and the American Epilepsy Society (AES) support the use of topiramate in conjunction with lamotrigine, as this combination seems to be particularly effective at reducing tonic/atonic seizures in LGS [48]. However, it should be noted that topiramate is associated with cognitive side effects including mental slowing and dysphasia [49], which may lead to poor retention rates [50].

\subsubsection{Felbamate}

Although felbamate is licensed in the US (Table 1), it is not commonly used as it carries a black box warning owing to the risk of aplastic anaemia and hepatic failure, two life-threatening AEs [51]. Due to this risk, it has not been approved by the European Medicines Agency (EMA) for any indication, although it may be available in some countries on a patient-by-patient basis [2]. The mechanism of action of the carbamate-type anticonvulsant is also not well understood. Early seizure models indicated that felbamate increases seizure threshold and prevents the spread of seizures in the brain [52], which may make the drug particularly effective against generalised tonic-clonic or partial seizures [53]. More recent studies suggest the drug primarily operates by reducing glutamatergic transmission, though it may also inhibit GABA-receptor binding along with voltage-gated sodium and calcium channels [54].

The approval of felbamate in the US is based on a doubleblind, placebo-controlled RCT involving 73 LGS patients (Table 2) [53]. Felbamate, which was titrated up over 14 days from $15 \mathrm{mg} / \mathrm{kg} /$ day to a maximum of $45 \mathrm{mg} / \mathrm{kg} /$ day or $3600 \mathrm{mg} /$ day, was associated with a $34 \%$ reduction in the frequency of atonic seizures, with five patients experiencing no atonic seizures while receiving their maximum dosage, compared with $9 \%$ in the placebo group (Table 2; Fig. 4). This decrease of atonic seizure counts showed a linear correlation with an increase in felbamate plasma concentrations as dosage increased. The drug was also effective against other seizure types with the frequency of total seizures reduced by $19 \%$ and four patients becoming seizure free in the felbamate-treated group, compared with a $4 \%$ increase in the placebo group (Table 2; Fig. 4). Importantly, evaluations revealed a significant increase in QoL for the patients taking felbamate compared with the placebo group, based on caregivers' impressions (Table 2). AEs were primarily mild or moderate, although the study had a small sample size and a relatively short 10 -week period of treatment.

Seventy of the patients who completed this trial continued in an open-label follow-up study, where those who were originally treated with placebo showed similar levels of improvement as the felbamate-treated patients [55]. During the original study, only five of 36 patients in the placebotreated group showed $a \geq 50 \%$ reduction in total seizure frequency, which increased to 21 patients after a month on felbamate. Only two of 22 patients in the placebo-treated group showed a $>50 \%$ reduction in atonic seizure frequency during the original trial [53], which then increased to 12 when these patients were treated with felbamate during the open-label study. In the follow-up study, control of atonic seizure frequency was maintained at 12 months, and 51\% of patients maintained a $\geq 50 \%$ reduction in total seizure frequency at this timepoint, suggesting relative long-term efficacy and a lack of tolerance. Due to the previously mentioned risk for felbamate-associated fatal AEs, it is generally recommended as a last resort for patients with highly refractory epilepsy (Fig. 3) [56]. However, despite the blackbox warning, several retrospective real-world clinical studies have found felbamate to be safe in the context of close monitoring of hepatic and haematologic functions, confirming that felbamate does have a place in the LGS treatment pathway [57-59]. 


\subsubsection{Steroids}

Steroids, including prednisone, prednisolone, methylprednisolone, adrenocorticotrophin hormone (ACTH) and hydrocortisone also have an important role during periods of heightened seizure activity. While the efficacy of steroids for infantile spasms has been established from RCTs [60], evidence for the treatment of other types of seizures is more limited, generally from observational studies [61]. In studies evaluating steroids in patients with refractory epilepsies other than infantile spasms that have included at least a few patients with LGS, responder rates of 30\%-79\% have been reported [62, 63]. However, the well documented side effects of prolonged steroid use, including hypertriglyceridaemia, osteoporosis and suppression of childhood growth means that their use should be curtailed to short-term 'crisis' periods [2].

\subsection{Third-Generation Antiseizure Treatment Licensed for LGS: Rufinamide}

Rufinamide is a triazole derivative structurally unrelated to other AEDs. The best characterised mechanism of action of rufinamide is the modulation of the activity of sodium channels, prolonging their inactive state, although it may have additional mechanisms through which it exerts its therapeutic effects [64-66]. Rufinamide failed to show efficacy in clinical studies in a general epilepsy population, while efficacy was observed in LGS patients. As such, rufinamide was approved in the EU in 2007 and in the US in 2008 as adjunctive therapy for the treatment of seizures associated with LGS in children and adults aged 4 years and older, which was expanded to include patients 1 year of age and older in 2015 in the US and in 2018 in the EU [65, 66].

\subsubsection{Pivotal Clinical Trials}

The FDA and EMA approvals in LGS were based on data from a phase III, double-blind, placebo-controlled RCT in patients with LGS aged 4-37 years (Study 022) [67], with the expanded indication from a phase III, open-label RCT in paediatric patients ( $\geq 1$ to $<4$ years old) (Study 303; ClinicalTrials.gov identifier NCT01405053) [68, 69].

Study 022 and OLE (Study 022E), conducted in 138 patients (74 in the rufinamide group and 64 in in the placebo group), consisted of a 4-week baseline period, a 12-week, double-blind treatment period, a 2-week, double-blind conversion phase, followed by an open-label single-arm extension period of up to 3 years $[67,70]$. Compared with placebo at 12 weeks, the median percentage reduction in both total seizure frequency and drop seizures was significantly greater in the rufinamide group compared with the placebo group (Table 2; Fig. 4). The rufinamide group had a larger improvement in seizure severity and a significantly higher $50 \%$ responder rate compared with placebo (Table 2; Fig. 4) [67]. The results are also supported by a phase III trial in Japan in patients aged 4-30 years, which showed that the frequency of epileptic seizures was significantly decreased in the rufinamide group compared with the placebo group; the median percent change in frequency of tonic-atonic seizures was $-24.2 \%$ and $-3.3 \%$, respectively, $(p=0.003)$ and that of total seizures was $-32.9 \%$ and $-3.1 \%$, respectively $(p<0.001)$ [71].

In Study 303, 37 paediatric patients randomised to rufinamide $(n=25)$ or any other $\operatorname{AED}(n=12)$ were evaluated across a 106-week treatment phase for safety/tolerability and behavioural effects assessed via the Child Behaviour Checklist (CBCL) [68, 69]. Overall, behavioural outcomes were comparable between the rufinamide and 'any other AED' groups, although the small sample size and difficulties assessing behaviour are important caveats that should be acknowledged (Table 2) [68]. In addition, in a post-hoc analysis, the mean number of seizure-free days was $42.2 \%$ greater post-baseline compared with baseline in patients treated with rufinamide $(p<0.0001)$, with only one rufinamide patient experiencing a decrease in the number of seizure-free days post-baseline [72]. The median time to reach the baseline number of seizures increased by 10.5 days for rufinamide and 0.5 days for the 'any other AED' group during the treatment phase, to 46.0 and 54.0 days, respectively.

\subsubsection{Longer-Term Data}

In Study 022E, 124 of the original 139 patients from Study 022 entered the extension study; patients were treated with rufinamide for a median (range) of 432 (10-1149) days [70]. Efficacy was sustained for both seizure frequency reduction and responder rates, with reductions in seizure frequency observed throughout the study; during the last 12 months of treatment, $41.0 \%$ and $47.9 \%$ of patients had $\geq 50 \%$ reduction in total and tonic-atonic seizure frequency, respectively. In addition, in another OLE, this time in Japanese patients with LGS who participated in the RCT, reduction of seizure frequency was maintained to 52 weeks [73].

\subsubsection{Safety}

Rufinamide is a generally well tolerated treatment. In Study 022, the most common AEs were somnolence (24.3\% with rufinamide vs $12.5 \%$ with placebo) and vomiting (21.6\% vs $6.3 \%$ ), and in Study 022E they were vomiting (30.6\%) and pyrexia $(25.8 \%)[67,70]$. In Study 022/022E, three patients in the rufinamide group experienced status epilepticus compared with none in the placebo group. In the paediatric population of patients aged $\geq 1$ to $<4$ years (Study 303), the frequency, type and severity of AEs were similar to that in 
children 4 years of age and older, adolescents and adults; the most frequently reported AEs in the rufinamide treatment group (occurring in $\geq 10 \%$ of subjects) were upper respiratory tract infection and vomiting ( $28 \%$ each), pneumonia and somnolence ( $20 \%$ each), diarrhoea, pyrexia, cough, sinusitis and otitis media (16\% each), and rash, irritability, decreased appetite, constipation, bronchitis and nasal congestion (12\% each) [68].

\subsubsection{Additional Prospective and Retrospective Clinical Studies}

Further to the pivotal phase III studies, the effectiveness and safety/tolerability of rufinamide in treating seizures associated with LGS has been supported by other clinical trials and several 'real-world' clinical practice studies; responder rates ( $\geq 50 \%$ reduction in seizures) ranging from 33.3 to $60.5 \%$ have been reported across the studies in LGS patients, and no new safety concerns have been identified [74-79]. The additional studies have been recently comprehensively reviewed by Balagura et al. [80] (2020) and by Striano et al. (2018) [81].

\subsubsection{Other Considerations: Drug-Drug Interactions}

The presence of possible interactions with other AEDs and other medications are also important aspects to be taken into consideration. Significant increases in rufinamide plasma concentrations may occur with concomitant valproate, and consequently a dose reduction of rufinamide may be required (Table 1) [65, 66]. In contrast, no significant changes in rufinamide concentration have been observed following co-administration with lamotrigine, topiramate or benzodiazepines. In addition, rufinamide appears not to have a clinically relevant effect on carbamazepine, lamotrigine, phenobarbital, topiramate, phenytoin or valproate steadystate concentrations $[65,66]$.

\subsection{Recently Approved Pharmacologic Treatment for LGS: Cannabidiol}

The full mechanisms of action by which cannabidiol exerts its anti-seizure effects are still being explored, although it is known that it possesses affinity for diverse targets that decrease the neuronal excitability related to the pathogenesis of the disease; cannabidiol targets include the $\mathrm{G}$ proteincoupled receptor 55 (GPR55) and transient receptor potential vanilloid 1 (TRPV-1) channels that modulate intracellular calcium, and the equilibrative nucleoside transporter 1 (ENT-1) involved in adenosine-mediated signalling [82, 83]. The anticonvulsant effect does not work via cannabinoid receptors, and this lack of appreciable affinity or activity at these receptors means that it is not associated with the psychoactivity of the archetypal cannabinoid, tetrahydrocannabinol [84].

Cannabidiol has been approved as adjunctive therapy for seizures associated with LGS or Dravet syndrome (DS) for patients 2 years of age and older since 2018 in the US and 2019 in the EU $[83,85]$; in the US the FDA has recently expanded the indication to include patients 1 year of age and older, as well as TSC patients (Table 1). In the EU it is approved in conjunction with clobazam because in the key pivotal trial this combination resulted in greater efficacy than in the subgroup of patients not taking clobazam (Table 2; Fig. 4) [83]. The recommended maintenance dose of the oral solution is $10 \mathrm{mg} / \mathrm{kg} / \mathrm{day}$, which can be increased to $20 \mathrm{mg} / \mathrm{kg} / \mathrm{day}$.

\subsubsection{Pivotal Clinical Trials}

The approvals from the FDA and EMA for LGS were informed by data from two phase III, double-blind, placebo-controlled, parallel-group RCTs. GWPCARE3 [86] and GWPCARE4 [87], which both consisted of a 14-week treatment period (2-week titration period and 12-week maintenance period), were conducted in LGS patients (aged 2-55 years) who were inadequately managed on at least two AEDs. In GWPCARE3, patients $(n=255)$ were randomised to receive cannabidiol at $20 \mathrm{mg} / \mathrm{kg}$ of body weight (CBD20 group; $n=76$ ) or $10 \mathrm{mg} / \mathrm{kg}$ (CBD10 group; $n=73)$ or matching placebo $(n=76)$. In GWPCARE4, 171 patients were randomised to receive cannabidiol at $20 \mathrm{mg} /$ $\mathrm{kg}(n=86)$ or matching placebo $(n=85)$. Across both trials, commonly used conventional AEDs that were used in $>25 \%$ of patients were valproate, clobazam, lamotrigine, levetiracetam and rufinamide, with approximately $50 \%$ of the patients taking concomitant clobazam.

Across the trials, cannabidiol was associated with statistically significant and clinically meaningful improvements in seizure frequency compared with placebo (Table 2; Fig. 4). Compared with placebo, cannabidiol was associated with a significantly higher percentage reduction in the monthly frequency of drop seizures during the 14-week treatment period in both trials (Table 2; Fig. 4). Furthermore, significantly higher percentages of patients in the cannabidiol groups achieved $\geq 50 \%$ reductions in the monthly frequency of drop seizures than in the placebo group (Table 2; Fig. 4). A few patients in the cannabidiol groups were drop-seizure free during the entire 12-week maintenance period, although not during the whole 14-week period that included the titration period, suggesting that cannabidiol might have a delayed effect on drop attacks. In addition, cannabidiol may have efficacy over a range of seizures types, with significant reductions in the median frequency for total seizures and non-drop seizures. In addition, cannabidiol treatment led to an increase in the number of drop seizure-free days of 
3.3 days per 28 days in the CBD10 group and 5.5 to 7.6 days per 28 days in the CBD20 groups. Furthermore, greater improvements in the Global Impression of Change scores (measuring overall condition) were reported by caregivers and patients with both doses of cannabidiol (Table 2).

\subsubsection{Longer-Term Data}

Patients who completed the pivotal phase III trials could enrol in an OLE study that evaluated the long-term safety and efficacy of cannabidiol (GWPCARE5, NCT02224573), with 366 (99.5\%) patients continuing in this OLE study [88]. Cannabidiol was associated with sustained reductions in seizures, evidenced by median reductions from baseline in drop seizure frequency ranging from 48 to $60 \%$ across 12 -week periods to week 48 , and total seizure frequency reductions ranging from 48 to $57 \%$. Furthermore, the vast majority $(88 \%)$ of patients/caregivers reported an improvement in the patient's overall condition assessed using the Subject/ Caregiver Global Impression of Change scale.

An expanded access programme in the US in children and adults with DS $(n=54)$ or LGS $(n=152)$ has also demonstrated long-term efficacy of cannabidiol across a median treatment duration of 78.3 (range 4.1-146.4) weeks [89]. For the pooled DS/LGS population, cannabidiol was associated with reductions at week 12 in median monthly major motor seizures of $50 \%$ and total seizures of $44 \%$, that persisted through week 96 . In addition, 53\% of patients had $\geq 50 \%$ reductions in major motor seizures and $46 \%$ in total seizures at 12 weeks, with consistent responder rates throughout the 96 weeks of treatment.

\subsubsection{Safety}

Cannabidiol was generally well tolerated across the LGS studies; the most common AEs in patients in the CBD groups in GWPCARE3 were somnolence, decreased appetite and diarrhoea, particularly in the CBD20 group; in GWPCARE4 they were diarrhoea, somnolence, pyrexia, decreased appetite and vomiting, and in the OLE the most common AEs were diarrhoea, somnolence and convulsion. Overall, in a pooled analysis of placebo-controlled trials of patients with LGS or DS ( $n=323$ patients receiving cannabidiol), the most common AEs in cannabidiol-treated patients with an incidence $\geq 10 \%$ (and greater than placebo) were related to poor sleep (insomnia, sleep disorder and poor quality sleep); somnolence; fatigue, malaise, and asthenia; decreased appetite; diarrhoea; transaminase elevations; rash; and infections [83, 85]. With regard to transaminase elevations, the risk factors include higher doses of cannabidiol, concomitant use of valproate and to a lesser extent concomitant use of clobazam, with this AE generally being resolved by reductions in the dose of cannabidiol and/or concomitant valproate $[83,85]$. In addition, the incidence of somnolence and sedation has also been shown to be doserelated, and is more common in patients on concomitant clobazam $[83,85]$.

\subsubsection{Other Considerations: Drug-Drug Interactions}

As discussed above, in the EU, cannabidiol is only indicated in conjunction with clobazam due to the increased efficacy observed in this subgroup of patients (Table 2; Fig. 4). A bidirectional drug-drug interaction occurs with the combination of cannabidiol with clobazam leading to increased levels of active metabolites of both compounds. While there has been speculation that the efficacy of cannabidiol may be due solely to an increase in the plasma concentration of clobazam, recent meta-analyses of trials in patients with DS and LGS have demonstrated that cannabidiol has benefits beyond the interaction with clobazam; although improvement in seizure control was indeed greatest in patients with cannabidiol and concomitant clobazam, efficacy was also improved compared with placebo in patients with other concomitant medications [90-92].

Increases in serum levels of topiramate and rufinamide (in adults and children), and zonisamide and eslicarbazepine (in adults) have been reported with increasing doses of cannabidiol, but were within the accepted therapeutic range [85]. In addition, a case series of five patients reported a marked increase in brivaracetam levels of $95 \%$ to $280 \%$, although only two patients reported AEs, which were mild, but resulted in a dose reduction of brivaracetam in one patient [93]. As discussed in the safety section, a clinically and statistically significant interaction with clobazam and its active metabolite $\mathrm{N}$-desmethylclobazam has been reported, resulting in increased sedation $[83,85,94,95]$ (Table 1). In addition, an interaction has been noted in patients taking concomitant valproate and cannabidiol with regard to elevated liver function test results (Table 1) [83, 85, 94]. Also of potential interest is a case report of a possible interaction with the oral anticoagulant warfarin, requiring a reduction in the dosage of warfarin to prevent potential bleeding complications [96]. Other considerations related to drug-drug interactions include reducing the cannabidiol dose when coadministered with a moderate or strong inhibitor of CYP3A4 or CYP2C19, and increasing the dose when coadministered with a strong CYP3A4 or CYP2C19 inducer [83, 85]. In addition, dose reductions of substrates of UGT1A9, UGT2B7, CYP2C8, CYP2C9, and CYP2C19 (e.g., clobazam) should be considered, and substrates of CYP1A2 and CYP2B6 may also require dose adjustment $[83,85]$. 


\subsection{Upcoming Pharmacologic Treatments: Agents in Phase III Clinical Development}

\subsubsection{Fenfluramine}

Fenfluramine is a derivative of amphetamine that was initially developed as an appetite suppressant [97]. fenfluramine acts via multiple receptors to exert its therapeutic effects for the treatment of seizures, although the exact mechanisms are still being elucidated. Fenfluramine increases extracellular levels of serotonin (5-HT) through interaction with serotonin transporter proteins, and exhibits agonist activity at serotonin 5HT-2 receptors (5HT1D and 5HT2C) [97-100]. In addition, at the in vitro and in vivo level, fenfluramine activity at 5-HT receptors is complemented synergistically by functional activation of sigma- 1 receptors, resulting in improved cognitive functions of spatial and contextual learning via activity at sigma-1 receptors in mouse models [101]. Fenfluramine was previously prescribed as an anorexigen, but it was withdrawn in 1997 based on reports of increased risks of cardiac valvulopathy and pulmonary hypertension in adult patients treated for obesity; however, the fenfluramine doses were much higher compared with a licensed maximum dose for DS, and it was frequently given off-label with phentermine, which itself has an impact on valvular disease [102-104]. In contrast, the benefit/risk profile of fenfluramine given at low dose for the treatment of seizures appears to be positive, and fenfluramine has been approved by the FDA in the US for the treatment of seizures associated with DS in patients age 2 years and older [98]. In December 2020 fenfluramine was approved by the EMA in the EU for the treatment of DS.

2.5.1.1 Pivotal Clinical Trial Fenfluramine is currently in late-stage phase III clinical development as a therapy for the treatment of uncontrolled seizures in children and adults with LGS. The phase III, multicentre, global, double-blind, placebo-controlled study (Study 1601 [NCT03355209]) enrolled 263 patients with LGS aged 2-35 years whose seizures were currently uncontrolled despite treatment with one or more AED(s) [105]. Patients were randomised into three treatment groups: fenfluramine $0.7 \mathrm{mg} / \mathrm{kg} / \mathrm{day}$ ( $26 \mathrm{mg}$ maximum daily dose; $n=87$; FFA0.7), fenfluramine $0.2 \mathrm{mg} / \mathrm{kg} / \mathrm{day}(n=89$; FFA0.2) and placebo $(n=87)$. With a median age of 13 years, $29 \%$ of patients were 18 years or older. Patients had had an average of seven prior AEDs and were taking between one and four AEDs at baseline. The median baseline drop seizure frequency across the study groups was 77 seizures per month. During Part 1 of the trial, baseline seizure frequency was established during the first 4 weeks, after which there was a 14-week treatment period consisting of a 2 -week titration period followed by a 12 -week fixed- dose maintenance period. Patients who completed Part 1 could enrol in an ongoing 12-month OLE study (Part 2), which was conducted to establish the long-term safety, tolerability and effectiveness.

Compared with placebo, patients in the FFA0.7 group had a significant median percent reduction in the frequency of monthly drop seizures from baseline, thereby meeting the study's primary endpoint (Table 2; Fig. 4). Using a parametric analysis, FFA0.7 was associated with a $26.5 \%$ greater reduction in mean monthly drop seizure frequency compared with placebo $(p=0.0034)$. On the other hand, the median percent reduction in monthly drop seizures for FFA0.2 did not reach statistical significance compared with placebo $(13.2 \% ; p=0.0915)$. Clinically meaningful $(\geq 50 \%)$ reductions in mean convulsive seizure frequency in monthly drop seizures were experienced in significantly more patients treated with FFA0.7 compared with placebo (Table 2; Fig. 4). In addition, using the Clinical Global Impression of Improvement (CGI-I) that assesses improvement or worsening relative to baseline as judged by the investigator, significantly more patients in the FFA 0.7 group than the placebo group were considered to be much improved or very much improved (Table 2).

2.5.1.2 Longer-Term Data The phase III study supports the results from an earlier, phase II, open-label, dosefinding study of add-on fenfluramine in patients with LGS (NCT02655198), which now has data for 15 months of treatment [99]. During the 20-week core study, there was a $53 \%$ median reduction $(n=13)$ in convulsive seizures, with eight patients $(62 \%)$ having a $\geq 50 \%$ reduction in convulsive seizures, while at 15 months (long-term extension; $n=9$ ), the median reduction in convulsive seizures was 58\%, with six (67\%) patients having a $\geq 50 \%$ reduction.

2.5.1.3 Safety Fenfluramine was generally well tolerated, with no new safety signals to those observed in the two DS studies (reviewed by Strzelczyk and Schubert-Bast 2020 [106]). Overall, $89.7 \%$ experienced at least one AE in the FFA0.7 group, $76.4 \%$ in the FFA0.2 group and $79.3 \%$ in the placebo group. Decreased appetite, somnolence, fatigue, vomiting, diarrhoea and pyrexia were the most common AEs $(\geq 10 \%)$ reported in the fenfluramine groups. SAEs occurred in $11.5 \%$ of patients $(n=10)$ in the FFA0.7 group, $4.5 \%$ $(n=4)$ in the FFA0.2 group and $4.6 \%(n=4)$ in the placebo group. AEs leading to study discontinuation occurred rarely, in six patients in the FFA 0.7 group, four in the FFA0.2 group and one in the placebo group, although the majority were considered as treatment-related. One patient died during the trial (FFA0.7 group) due to SUDEP (sudden unexpected death in epilepsy) that was unrelated to the study drug as assessed by the investigator. A total of 247 (93.9\%) 
patients entered the OLE phase. Similarly, in the phase II study, the most common AEs included decreased appetite $(31 \%[n=4])$ and decreased alertness $(15 \%[n=2])$. No cases of valvular heart disease or pulmonary hypertension were observed in either the phase III trial (both Part 1 and Part 2) or in the phase II study.

\subsubsection{Other Considerations: Drug-Drug Interactions No} significant impact on the pharmacokinetics of clobazam, valproate and cannabidiol has been observed with fenfluramine $[107,108]$. A combination of stiripentol with valproate + clobazam led to an increase in the peak plasma levels and systematic exposure of fenfluramine, requiring a reduction in the dose of fenfluramine (to a maximum dose of $0.4 \mathrm{mg} / \mathrm{kg} /$ day) when administered in combination with the stiripentol regimen, although this is more relevant to the treatment of DS [107, 109].

\subsubsection{Perampanel}

Perampanel is a selective, non-competitive antagonist of the ionotropic $\alpha$-amino-3-hydroxy-5-methyl-4isoxazolepropionic acid (AMPA) glutamate receptor on post-synaptic neurons, although the precise mechanisms by which it exerts its antiepileptic effects are not yet fully understood [110, 111]. Perampanel is currently approved by the EMA and the FDA in patients with epilepsy aged 12 years and older as an adjunctive therapy for the treatment of partial-onset seizures with or without secondarily generalised seizures and for primary generalised tonic-clonic seizures $[110,111]$.

Perampanel is currently being investigated in a phase III, multicentre, double-blind, placebo-controlled RCT as adjunctive therapy in patients with inadequately controlled seizures associated with LGS (NCT02834793) [112]. With an estimated enrolment of 142 patients, and a primary endpoint of median percent change in drop seizure frequency per 28 days during double-blind treatment, the primary completion date is estimated to be in January 2022 [112].

While no results have been reported from the clinical trial to date, the efficacy and safety of perampanel in LGS patients has been demonstrated in retrospective, open-label, observational studies [113-118]. Response rates $(\geq 50 \%$ seizure reduction) of $64.8 \%$ (46/71 adult patients [113]) and $69.2 \%$ (9/13 children/adolescents [117]) have been reported in LGS patients. In addition, in a large real-world study of 2396 individuals with treatment-resistant epilepsy who were treated with add-on perampanel, $9 \%$ were seizure free for $\geq 6$ months, and the 1-year retention rate was 48\% [118]. In 388 individuals with available data, responder rates were $42 \%$ at 3 months, $46 \%$ at 6 months and $39 \%$ at 12 months, and no new safety signals were observed. Further studies in mixed epileptic populations have also reported response rates of $46 \%$ (34/74 children/adolescents with various refractory epilepsies [5 with LGS] [116]) and 31\% (18/58 difficult-to-treat epilepsy patients [4 with LGS] [114]). Perampanel was generally well tolerated, with typical AEs being dizziness, somnolence and fatigue [113-117]. In addition, improvements in cognitive function and/or behaviour were reported in a proportion of patients: 7/13 (53.8\%) children/ adolescents with LGS [117], and 4/71 (5.6\%) adult patients with LGS [113], although conversely, perampanel can also be associated with psychiatric AEs including irritability and aggression that may be more marked in those with cognitive impairment [119]. Perampanel is already used in LGS patients off-label (Fig. 3), while positive data from the phase III study may lead to a specific indication for LGS.

\subsection{Off-Label AEDs}

Some other AEDs, including levetiracetam and zonisamide, may also be useful in treating multiple seizure types because of their broad spectrum in their modes of action. Zonisamide, which is approved by the FDA and EMA as an adjunctive therapy for the treatment of partial seizures in adults and children aged 6 years and above, is thought to act through various mechanisms, including blocking sodium and T-type calcium channels, resulting in increased dopamine and serotonin neurotransmission, as well as blocking glutamate release [120]. In a study of 62 children with LGS treated with zonisamide, three patients were seizure free and $51.6 \%$ of patients experienced $a \geq 50 \%$ reduction in seizure frequency [120]. In addition, among 55 children with LGS, levetiracetam was associated with a reduction in seizure frequency of $\geq 50 \%$ in $58.2 \%$, with 15 patients (27.3\%) being seizure free [121]. Levetiracetam in particular is a common choice owing to its generally good safety and tolerability profile as well as having few interactions with other medications, although it can be associated with psychobehavioural AEs, especially in children and in patients with cognitive impairment [122]. The therapeutic indications for levetiracetam in the US and EU include the treatment of partial-onset seizures, and it may exert its effects through various mechanisms, including affecting intraneuronal $\mathrm{Ca}^{2+}$ levels and/or by its interaction with synaptic vesicle protein 2A [122]. However, it should be noted that overall there is a paucity of evidence regarding zonisamide and levetiracetam in LGS, generally garnered from a few observational studies (reviewed in Cross et al. 2017 [2]), and robust evidence from RCTs is lacking.

There has also been recent evidence of a newer AED, brivaracetam, showing efficacy in patients with epileptic encephalopathies, including LGS [123-125]. Brivaracetam is a levetiracetam analogue that binds to the synaptic vesicle protein $2 \mathrm{~A}$, and inhibits excitatory neurotransmitters' release [126, 127]. It was approved in the US and the EU in 2016 as adjunctive treatment for focal-onset seizures in patients over 16 years of age, 
and in 2018 for children over 4 years of age. In a cohort study in Germany ( $n=44,20$ [45.5] with LGS), a 50\% responder rate was reported in 19 patients (43\%); nine patients (20\%) were seizure free for $>12$ months, and two were seizure free for $>6$ months [125]. AEs, observed in only $16 \%$ of patients, were predominantly of psychobehavioural in nature; the rate was lower than had been reported in patients on levetiracetam at switch (32\%), suggesting that brivaracetam may be a suitable alternative for those who experience psychobehavioural AEs associated with levetiracetam. Similarly, in a large population of patients with predominantly drug-resistant epilepsy $(n=575)$, brivaracetam was shown to be effective and well tolerated, with a $\geq 50 \%$ responder rate of $39.7 \%$, and $17.5 \%$ being seizure free; tolerability was not highly affected in patients with learning disability or psychiatric comorbidity [124]. Finally, in another observational study that included 31 patients, of whom 11 had epileptic syndromes ( 5 with LGS), the responder rate was $45.2 \%$, and eight patients had better response to seizures compared with levetiracetam. In addition, AEs were rare (mild somnolence [6.4\%], psychosis [3.2\%] and nausea [3.2\%]) [123].

Other AEDs including phenobarbital, ethosuximide and bromides are also sometimes used, despite a lack of goldstandard evidence from RCTs [31]. Carbamazepine, oxcarbazepine, eslicarbazepine, tiagabine, phenytoin, vigabatrin, pregabalin and gabapentin are infrequently used, and there may be potential for aggravating certain seizure types with these AEDs $[2,17]$.

\subsection{Pharmacologic Agents in Earlier Clinical Development}

\subsubsection{Soticlestat-OV953/TAK-953}

Soticlestat (TAK-935/OV935) is a novel, highly selective first-in-class inhibitor of the brain-specific enzyme cholesterol 24-hydroxylase $(\mathrm{CH} 24 \mathrm{H})$ that dose-dependently reduces plasma levels of $24 \mathrm{~S}$ hydroxycholesterol (24HC) [128]. $24 \mathrm{HC}$ is an endogenous positive allosteric modulator of NMDA receptors [128], which are a subtype of glutamate receptors that play important roles in excitatory neurotransmission and synaptic plasticity implicated in several neurological diseases, including epilepsy [129]. Soticlestat has shown anticonvulsant activity in animal seizure models, and a correlation between reduction in $24 \mathrm{HC}$ levels and reduced seizure frequency was observed in a phase Ib/IIa study [130].

Soticlestat is being evaluated in two phase II trials for DEEs including LGS-ELEKTRA and ENDYMION. The ELEKTRA trial (NCT03650452) is a phase II, multicentre, double-blind, placebo-controlled RCT designed to evaluate the efficacy, safety and tolerability of soticlestat in paediatric patients, aged $2-17$ years old, with DS $(n=51)$ or LGS $(n=88)$ [131]. The top-line results have recently (late August 2020) been announced, reporting that the study met its primary endpoint, with a $27.8 \%$ median reduction from baseline in convulsive seizure (DS) and drop seizure (LGS) frequency compared with a $3.1 \%$ median increase in patients taking placebo during the 12 -week maintenance period (median placebo-adjusted reduction: $30.5 \% ; p=0.0007, n=120$ patients with seizure data in the maintenance period) [132]. In the LGS cohort, soticlestat was associated with a $20.6 \%$ median reduction in drop seizure frequency versus $6.0 \%$ with placebo (median placebo-adjusted reduction in seizure frequency: $14.8 \%$; $p=0.1279)$. In addition, $27.9 \%$ of LGS patients showed an improvement according to the investigator-assessed Global Impression of Change. Soticlestat was well tolerated, with the most frequent AEs with a $\geq 5 \%$ difference from placebo being lethargy and constipation.

The long-term safety and tolerability of soticlestat is also being evaluated in ENDYMION (NCT03635073), a phase II, multicentre, open-label, long-term extension study of soticlestat in adult patients (18-65 years) with DEEs who participated in the phase Ib/IIa study [133]. Following on from the phase Ib/IIa study which showed a $36 \%$ median reduction in seizure frequency from baseline to day $85(n=16)$ [134], initial results from ENDYMION have reported a median seizure frequency reduction of $46.4 \%$ following $13-24$ weeks $(n=7), 82 \%$ following 25-36 weeks $(n=7)$, and 90\% following 37-48 weeks $(n=4)$ of treatment. In addition, the longest seizure-free consecutive duration by two different participants was 264 days (out of 350 treatment days) and 150 days (out of 336 treatment days), respectively. Soticlestat was generally well tolerated, with the majority of reported AEs being mild in severity, and no SAEs were observed.

\subsubsection{Carisbamate}

Carisbamate is being evaluated in a phase I, open-label, multicentre study in adult and paediatric patients with LGS (NCT03731715), with an estimated study completion date of September 2020 [135]. Carisbamate previously failed to show efficacy in a phase III study in patients with partialonset seizures; however, given its wide spectrum of anticonvulsant activity in preclinical models, it is now being investigated in LGS patients [22, 130, 136]. Carisbamate belongs to the carbamate drug family, characterised by a key structural motif [137], which also includes felbamate (described above) and cenobamate; the latter was FDA approved in late 2019 for the treatment of partial seizures in adult patients, and is currently being assessed by the EMA [138].

\subsubsection{Ganaxolone}

Ganaxolone is a GABA-A receptor modulator, which activates synaptic and extrasynaptic GABA-A receptors at a site 
distinct from benzodiazepines and barbiturates [139]. In an open-label trial, ganaxolone was assessed in eight children with LGS (aged 2-15 years) with severe, treatment-resistant generalised tonic-clonic and drop seizures [139]. The median percentage change at 26 weeks for major seizures was $-32 \%$ (range -80 to $+40 \% ; p=0.195$ ), and the median percentage change for seizure-free days was $+33 \%$ (range 0 to $+170 \%$ $p=0.031)$. No SAEs were reported. Marinus Pharmaceuticals is currently conducting studies evaluating ganaxolone in CDKL5 deficiency disorder, PCDH19-related epilepsy and refractory status epilepticus [140]; however, it is not clear if any further studies in LGS patients are planned.

\section{Non-Pharmacologic Agents}

\subsection{Ketogenic Diet}

The ketogenic diet (KD) is a diet that is high in fat and low in carbohydrate with adequate protein, with strictly controlled amounts and ratios of fat to a combination of protein and carbohydrates [141]. The KD mimics the fasting state, characterised by systemic ketosis, with elevations in the concentrations of the ketone bodies, beta-hydroxybutyrate, acetoacetate and acetone [142]. The KD and related diets have been shown to be useful in various pharmacoresistant childhood epilepsies, including LGS [141]. While the mechanism of action for the KD's anticonvulsant effects are unknown, theories include modulation by the ketone bodies on glutamatergic and GABAergic neurotransmitter metabolism, glycolytic restriction/diversion, improved cellular bioenergetics, mitochondrial function and reduced oxidative stress, direct inhibitory effects of fatty acids, and enhancement of the tricarboxylic acid cycle [141-143].

Recent systematic literature reviews and meta-analyses have provided a useful synthesis of the evidence regarding the efficacy and safety of the KD in patients with refractory epilepsy, albeit not specific to LGS. A Cochrane Database Systematic Review conducted in 2018 identified 11 RCTs evaluating the KD for drug-resistant epilepsy: the proportion of patients achieving $\geq 50 \%$ reduction in seizure frequency ranged from $35 \%$ to $56 \%$ in the KD groups compared with $0 \%$ to $18 \%$ in the control groups, and the proportion achieving seizure freedom ranged from 0 to $15 \%$ in the KD groups versus 0\% to 9\% in the control groups [144]. Further to this, a meta-analysis of 16 observational studies in adult patients with intractable epilepsy reported that the combined responder rate ( $\geq 50 \%$ seizure reduction) was $53 \%$ and the rate of seizure freedom was 13\% [145]. The adverse reactions of the KD were mild. In addition, Lyons et al. recently (2020) conducted a systematic review of the KD specifically in infants aged $<2$ years with drug-resistant epilepsy, that identified 33 studies (2 RCTs and 31 uncontrolled cohort studies), with a total of 534 infants with efficacy data [146]. Meta-analyses of the uncontrolled studies estimated that $59 \%$ of infants achieved $\geq 50 \%$ seizure reduction and 33\% of infants achieved seizure freedom. The KD was well tolerated in this population, with the most common AEs being dyslipidaemia (12\%), vomiting (6\%), constipation (4\%), gastroesophageal reflux (4\%), and diarrhoea (4\%). However, this latter study may have limited generalisability to LGS, since a firm diagnosis of LGS is only rarely made at this young age, when associated with specific aetiologies such as anoxicischaemic encephalopathy that may develop into LGS.

With respect to studies conducted solely in patients with LGS, there has been a number of open-label studies that have reported $\geq 50 \%$ responder rates of $40-51 \%$, and seizure freedom in $1-15 \%$ of patients, and have generally found the KD to be well tolerated [147-150]. The KD may also provide benefits beyond seizure control, with a systematic review reporting that the $\mathrm{KD}$ was associated with subjective improvements in alertness, attention, and global cognition in patients with refractory epilepsy [151]. However, diet adherence can be an obstacle to successful KD implementation, particularly in adults $[152,153]$.

\subsection{Vagus Nerve Stimulation}

Vagus nerve stimulation (VNS), which consists of intermittent electrical stimulation of the left cervical vagus nerve by an implanted helical electrode that is connected to a pulse generator, is a well-established procedure in drug-resistant epilepsy, with some evidence of efficacy in LGS. An evidence-based guideline update regarding VNS for the treatment of epilepsy from the AAN concluded that VNS could possibly achieve $>50 \%$ seizure reduction in $55 \%$ of patients with LGS, based on four studies [154]. However, it should be noted that corpus callosotomy (discussed in the following section) may have a better outcome than VNS for reduction of atonic seizures [155-157].

\subsection{Corpus Callosotomy}

Corpus callosotomy is a palliative surgical procedure for patients with refractory epilepsy, which involves cutting the corpus callosum, the bundle of nerve fibres that connects the two cerebral hemispheres, thereby preventing epileptic discharges and seizure patterns from propagation to both hemispheres. It is especially targeted for those patients with drop attacks [2]. Corpus callosotomy is performed either as an anterior two-thirds disconnection of corpus callosum or as a complete disconnection [158], generally performed either through an open approach via a standard craniotomy with the aid of an operating microscope, or alternatively via a mini-craniotomy with endoscope assistance, with the latter having the benefit of a smaller incision, minimised 
brain retraction, and lower postoperative pain [158]. More recently, a minimally invasive method-magnetic resonance imaging (MRI)-guided stereotactic laser interstitial thermal therapy (LITT) - has shown promising results in case reports [159-167]. In the largest study to date, investigating MRI-guided stereotactic laser anterior corpus callosotomy (SLACC) in 10 patients with LGS (median age 33 years, range $11-52$ years), eight ( $80 \%$ ) patients had $>80 \%$ reduction in drop attacks, of whom five (50\%) became free of drop attacks, and six $(60 \%)$ achieved $>80 \%$ seizure reduction, with two (20\%) becoming seizure free [167]. In addition, the complications of SLACC were minimal (one asymptomatic tract haemorrhage and no cases of disconnection syndrome), and patients had short hospital stays and minimal postoperative discomfort. However, it should be noted that the decision to perform corpus callosotomy should only be taken by medical teams with expertise in rare epilepsies and performed by neurosurgeons with the appropriate experience in epilepsy surgery.

\subsection{Resective Epilepsy Surgery}

Resective surgery in LGS patients is generally only recommended in a very few select patients with structural aetiology who have lesions predominantly in one hemisphere or TSC $[1,2,168]$. A recent study from Korea reported on the longterm outcomes of resective epilepsy surgery in 90 patients with LGS with focal epileptic pathology (mean age \pm standard deviation: $9.3 \pm 4.4$ years, range 3-23.5 years) [169]. With an average post-operative follow-up of $6.1 \pm 2.2$ years (range 2.1-11.4 years), 45 patients (50.0\%) had no seizures, and $15(16.7 \%)$ reported infrequent seizures. Of note, seizurefree patients achieved better adaptive behaviour and social competence than did patients with persistent seizures at the second follow-up (2-3 years after surgery) and third followup (4-6 years after surgery), and a shorter latent period from seizure onset to surgery led to a better level of adaptive behavioural functioning. The authors concluded that early and intensive investigations to determine eligible patients with focal aetiology are important for achieving improvements in behavioural functioning. However, overall, the evidence regarding resective epilepsy surgery in LGS patients is limited, and no controlled trials have been reported.

\section{Discussion}

Despite valproate never being specifically licensed for use in LGS, it is generally recommended as a good first-line option due to its broad spectrum and a low risk of seizure aggravation [1, 2, 23] (Fig. 2). However, in the vast majority of cases, valproate therapy is insufficient for adequate seizure control. Evidence of efficacy from placebo-controlled clinical trials, leading to approvals specifically for LGS in the US, has been available for lamotrigine, topiramate and felbamate since the 1990s, and more recently from rufinamide (2008) and clobazam (2011). Cannabidiol is the most recent, and welcome, addition to the treatment landscape. Fenfluramine, which was recently approved for the treatment of seizures associated with DS, is also in late-stage development for LGS, and perampanel, which is approved for seizures of focal and generalised onset already used off-label in LGS patients, is also being evaluated in LGS patients in a phase III trial. Evidence from observational studies suggests that brivaracetam may also have benefits for patients with drug-resistant epilepsy, including LGS patients. Nonpharmacologic interventions are also expanding, with the potential for less invasive techniques for corpus callosotomy that have promise for reducing complications, while recent systematic reviews have provided further consolidated evidence of the benefits of the KD.

There has been a lack of direct head-to-head studies to determine the comparative efficacy of the various treatments [170]. Indeed, this may not be easy or appropriate for LGS; because of the heterogeneous nature of the syndrome, both between patients and over time in the same patient, there cannot be a 'one size fits all' approach to treatment [2, 21-24]. A personalised approach, tailored to the individual symptoms and responses of the patient during all stages of care, with regular assessment of treatment options, is particularly important for a syndrome such as LGS. In this respect, having more choices that will fit patient's needs is clearly beneficial, although it also provides challenges to clinicians in selecting the best treatment or combination of treatments for their patients, whereby they must balance trade-offs between efficacy and side effects, taking into account the evidence from clinical trials (Table 2) and realworld studies, personal experience, as well as country availability. In this review, we have provided a comprehensive overview of the recent literature surrounding the efficacy and safety of treatments for LGS, with the aim of providing a useful resource for scientists and clinicians.

There are some limitations regarding the trials for LGS across the board that warrant some discussion. The trials were designed to evaluate the control of countable motor seizures, as opposed to specifically evaluating tonic or myoclonic seizures, which would need continuous video EEG monitoring. Therefore, the results regarding the total number of seizures (Table 2, Fig. 4) should be interpreted with the caveat that they do not encompass all the seizure types associated with LGS, and are therefore likely to represent an estimate of the actual total seizures.

It should also be noted that the therapeutic goals are shifting from symptom control (i.e. seizure freedom) towards QoL outcomes [2, 6]. Measuring QoL can be challenging in complex childhood syndromes, especially in instances where 
children are young and/or cognitively impaired [171, 172]; however, there has been more emphasis on outcomes that have an impact on QoL in more recent trials. Cannabidiol and fenfluramine are both associated with improvements in the patient's overall condition as per the Global Impression of Change, and cannabidiol was also associated with an increase in the number of drop seizure-free days. Further analysis of these newer treatments, as well as the 'older' treatments, are needed to assess their long-term impact on the QoL of patients, and also their caregivers.

The currently available treatments for LGS are primarily focussed on the control of seizures, with little evidence of an impact on the intellectual disability and behavioural aspects. This may require advances in two areas in particular; firstly, improvements in early diagnosis so that patients can be appropriately treated before there is irreparable damage to brain structures, which occurs in infants and children in the early stages of the syndrome [6]; and secondly, a more comprehensive understanding of the neurobiology of the syndrome is required with the aim of developing targeted therapies to the electro-clinical complex of LGS itself as well as the underlying aetiologies that can improve cognition and behaviour in addition to seizures. Of note, fenfluramine has shown improvements in emotion and behaviour regulation in DS, which may provide some hope in LGS patients, although there is no evidence to date of this benefit in LGS patients [101, 173-175]. A recent observational prospective study found that rufinamide was not associated with any statistically significant changes in cognitive, adaptive function and emotional aspects in LGS patients $(N=16$, mean age 22 years) with a follow-up of 1 year, demonstrating neither a positive nor a negative effect on these outcomes [176].

\section{Conclusion}

Despite recent breakthroughs, with newly approved and up-coming treatments, patients continue to experience a significant burden. Because LGS is not a single entity, tailoring of treatment is needed as opposed to a 'one size fits all' approach. Further research is needed into the underlying aetiologies and pathophysiology of LGS, together with advancements in treatments that encompass the spectrum of seizures associated with this complex syndrome.

Acknowledgements We would like to thank Amanda Prowse (Lochside Medical Communications Ltd) for providing medical writing assistance. Medical writing assistance was funded by GW Pharma (Germany) GmbH.

\section{Declarations}

Funding Open Access funding enabled and organized by Projekt DEAL. The authors did not receive funding for the preparation of this article.

Conflict of interest A. Strzelczyk reports personal fees and grants from Arvelle Therapeutics, Desitin Arzneimittel, Eisai, GW Pharmaceuticals, LivaNova, Marinus Pharmaceuticals, Medtronic, UCB Pharma and Zogenix. S. Schubert-Bast reports personal fees from Eisai, Desitin Pharma, GW Pharmaceuticals, LivaNova, UCB Pharma and Zogenix.

Ethics approval Not applicable.

Consent to participate Not applicable.

Consent for publication Not applicable.

Availability of data and material Not applicable.

Code availability Not applicable.

Author contributions Both authors reviewed the literature, drafted the manuscript, generated the figures, and assume full responsibility for the final publication.

Open Access This article is licensed under a Creative Commons Attribution-NonCommercial 4.0 International License, which permits any non-commercial use, sharing, adaptation, distribution and reproduction in any medium or format, as long as you give appropriate credit to the original author(s) and the source, provide a link to the Creative Commons licence, and indicate if changes were made. The images or other third party material in this article are included in the article's Creative Commons licence, unless indicated otherwise in a credit line to the material. If material is not included in the article's Creative Commons licence and your intended use is not permitted by statutory regulation or exceeds the permitted use, you will need to obtain permission directly from the copyright holder. To view a copy of this licence, visit http://creativecommons.org/licenses/by-nc/4.0/.

\section{References}

1. Crespel A, Gelisse P, Macorig G, Nikanorova M, Ferlazzo E, Genton P. Lennox-Gastaut syndrome. In: Bureau M, Genton P, Dravet C, Delgado-Escueta AV, Guerrini R, Tassinari CA, et al., editors. Epileptic syndromes in infancy, childhood and adolescence. 6th ed. Arcueil: John Libbey Eurotext; 2019.

2. Cross JH, Auvin S, Falip M, Striano P, Arzimanoglou A. Expert opinion on the management of Lennox-Gastaut syndrome: treatment algorithms and practical considerations. Front Neurol. 2017;8:505.

3. Cuomo A, Riel-Romero RM. Lennox gastaut syndrome. Treasure Island: StatPearls Publishing; 2020.

4. Smith KM, Britton JW, Cascino GD. Late-onset Lennox-Gastaut syndrome: diagnostic evaluation and outcome. Neurol Clin Pract. 2018;8(5):397-402. 
5. Arzimanoglou A, French J, Blume WT, Cross JH, Ernst JP, Feucht M, et al. Lennox-Gastaut syndrome: a consensus approach on diagnosis, assessment, management, and trial methodology. Lancet Neurol. 2009;8(1):82-93.

6. Resnick T, Sheth RD. Early diagnosis and treatment of LennoxGastaut syndrome. J Child Neurol. 2017;32(11):947-55.

7. Nariai H, Duberstein S, Shinnar S. Treatment of epileptic encephalopathies: current state of the art. J Child Neurol. 2018;33(1):41-54

8. Asadi-Pooya AA. Lennox-Gastaut syndrome: a comprehensive review. Neurol Sci. 2018;39(3):403-14.

9. Guerrini R, Marini C. West syndrome and Lennox-Gastaut syndrome. In: Shorvon SD, Anderman F, Guerrini R, editors. The causes of epilepsy: common and uncommon causes in adults and children. Cambridge: Cambridge University Press; 2011. p. 119-34.

10. Gallop K, Wild D, Nixon A, Verdian L, Cramer JA. Impact of Lennox-Gastaut Syndrome (LGS) on health-related quality of life (HRQL) of patients and caregivers: literature review. Seizure. 2009;18(8):554-8.

11. Gallop K, Wild D, Verdian L, Kerr M, Jacoby A, Baker G, et al. Lennox-Gastaut syndrome (LGS): development of conceptual models of health-related quality of life (HRQL) for caregivers and children. Seizure. 2010;19(1):23-30.

12. Gibson PA. Lennox-Gastaut syndrome: impact on the caregivers and families of patients. J Multidiscip Healthc. 2014;7:441-8.

13. Autry AR, Trevathan E, Van Naarden BK, Yeargin-Allsopp M. Increased risk of death among children with Lennox-Gastaut syndrome and infantile spasms. J Child Neurol. 2010;25(4):441-7.

14. Camfield PR. Definition and natural history of Lennox-Gastaut syndrome. Epilepsia. 2011;52(Suppl 5):3-9.

15. Camfield PR, Gibson PA, Douglass LM. Strategies for transitioning to adult care for youth with Lennox-Gastaut syndrome and related disorders. Epilepsia. 2011;52(Suppl 5):21-7.

16. Nabbout R, Andrade DM, Bahi-Buisson N, Cross H, Desquerre I, Dulac O, et al. Outcome of childhood-onset epilepsy from adolescence to adulthood: transition issues. Epilepsy Behav. 2017;69:161-9.

17. Montouris G, Aboumatar S, Burdette D, Kothare S, Kuzniecky R, Rosenfeld W, et al. Expert opinion: proposed diagnostic and treatment algorithms for Lennox-Gastaut syndrome in adult patients. Epilepsy Behav. 2020;110:107146.

18. Reaven NL, Funk SE, Montouris GD, Saurer TB, Story TJ. Burden of illness in patients with possible Lennox-Gastaut syndrome: a retrospective claims-based study. Epilepsy Behav. 2018;88:66-73.

19. Piña-Garza JE, Montouris GD, Vekeman F, Cheng WY, Tuttle E, Giguere-Duval P, et al. Assessment of treatment patterns and healthcare costs associated with probable Lennox-Gastaut syndrome. Epilepsy Behav. 2017;73:46-50.

20. Strzelczyk A, Schubert-Bast S, Simon A, Wyatt G, Holland R, Rosenow F. Epidemiology, healthcare resource use, and mortality in patients with probable Lennox-Gastaut syndrome: a population-based study on German health insurance data. Epilepsy Behav. 2020. https://doi.org/10.1016/j.yebeh.2020.107647

21. Strzelczyk A, Reese JP, Dodel R, Hamer HM. Cost of epilepsy: a systematic review. Pharmacoeconomics. 2008;26(6):463-76.

22. Auvin S. Lennox-Gastaut syndrome: new treatments and treatments under investigation. Revue Neurol. 2020;176(6):444-7.

23. Ostendorf AP, Ng YT. Treatment-resistant Lennox-Gastaut syndrome: therapeutic trends, challenges and future directions. Neuropsychiatr Dis Treat. 2017;13:1131-40.

24. Verrotti A, Striano P, Iapadre G, Zagaroli L, Bonanni P, Coppola $\mathrm{G}$, et al. The pharmacological management of Lennox-Gastaut syndrome and critical literature review. Seizure. 2018;63:17-25.
25. Hancock EC, Cross HH. Treatment of Lennox-Gastaut syndrome. Cochrane Database Syst Rev. 2009;8(3):cd003277.

26. Magiorkinis E, Diamantis A, Sidiropoulou K, Panteliadis C. Highights in the history of epilepsy: the last 200 years. Epilepsy Res Treat. 2014;2014:582039.

27. Michoulas A, Farrell K. Medical management of lennox-gastaut syndrome. CNS Drugs. 2010;24(5):363-74.

28. Sills GJ. Mechanisms of action of antiepileptic drugs. In: RuggGunn FJ, Sander JW, Smalls JE, editors. Epilepsy 2011: from sciences to society. A practical guide to epilepsy. 13th ed. London: International League Against Epilepsy; 2011.

29. Covanis A, Gupta AK, Jeavons PM. Sodium valproate: monotherapy and polytherapy. Epilepsia. 1982;23(6):693-720.

30. Ferrie CD, Patel A. Treatment of Lennox-Gastaut syndrome (LGS). Eur J Paediatr Neurol. 2009;13(6):493-504.

31. van Rijckevorsel K. Treatment of Lennox-Gastaut syndrome: overview and recent findings. Neuropsychiatr Dis Treat. 2008;4(6):1001-19.

32. Purcarin G, Ng Y-T. Experience in the use of clobazam in the treatment of Lennox-Gastaut syndrome. Ther Adv Neurol Disord. 2014;7(3):169-76.

33. Conry JA, Ng Y-T, Paolicchi JM, Kernitsky L, Mitchell WG, Ritter FJ, et al. Clobazam in the treatment of Lennox-Gastaut syndrome. Epilepsia. 2009;50(5):1158-66.

34. Ng YT, Conry JA, Drummond R, Stolle J, Weinberg MA. Randomized, phase III study results of clobazam in Lennox-Gastaut syndrome. Neurology. 2011;77(15):1473-81.

35. Conry JA, Ng YT, Kernitsky L, Mitchell WG, Veidemanis R, Drummond R, et al. Stable dosages of clobazam for LennoxGastaut syndrome are associated with sustained drop-seizure and total-seizure improvements over 3 years. Epilepsia. 2014;55(4):558-67.

36. Isojarvi J, Gidal BE, Chung S, Wechsler RT. Optimizing clobazam treatment in patients with Lennox-Gastaut syndrome. Epilepsy Behav. 2018;78:149-54.

37. Motte J, Trevathan E, Arvidsson JFV, Barrera MN, Mullens EL, Manasco P. Lamotrigine for generalized seizures associated with the Lennox-Gastaut syndrome. N Engl J Med. 1997;337(25):1807-12.

38. Yonemoto L. Lamotrigine. In: Sinatra RS, Jahr JS, WatkinsPitchford JM, editors. The essence of analgesia and analgesics. Cambridge: Cambridge University Press; 2010. p. 306-9.

39. Buchanan N. The efficacy of lamotrigine on seizure control in 34 children, adolescents and young adults with intellectual and physical disability. Seizure Eurx J Epilepsy. 1995;4(3):233-6.

40. Marciani MG, Spanedda F, Bassetti MA, Maschio M, Gigli GL, Mattia D, et al. Effect of lamotrigine on EEG paroxysmal abnormalities and background activity: a computerized analysis. Br J Clin Pharmacol. 1996;42(5):621-7.

41. Boas J, Dam M, Friis ML, Kristensen O, Pedersen B, Gallagher J. Controlled trial of lamotrigine (Lamictal ${ }^{\circledR}$ ) for treatmentresistant partial seizures. Acta Neurol Scand. 1996;94(4):247-52.

42. Brodie MJ, Sills GJ. Combining antiepileptic drugs-rational polytherapy? Seizure. 2011;20(5):369-75.

43. Vázquez M, Maldonado C, Guevara N, Rey A, Fagiolino P, Carozzi A, et al. Lamotrigine-valproic acid interaction leading to Stevens-Johnson Syndrome. Case Rep Med. 2018;2018:5371854.

44. Faught E. Topiramate in the treatment of partial and generalized epilepsy. Neuropsychiatr Dis Treat. 2007;3(6):811-21.

45. Sachdeo RC, Glauser TA, Ritter F, Reife R, Lim P, Pledger G. A double-blind, randomized trial of topiramate in Lennox-Gastaut syndrome. Neurology. 1999;52(9):1882-7.

46. Coppola G, Caliendo G, Veggiotti P, Romeo A, Tortorella G, De Marco P, et al. Topiramate as add-on drug in children, adolescents and young adults with Lennox-Gastaut syndrome: an Italian multicentric study. Epilepsy Res. 2002;51(1-2):147-53. 
47. Glauser TA, Levisohn PM, Ritter F, Sachdeo RC. Topiramate in Lennox-Gastaut syndrome: open-label treatment of patients completing a randomized controlled trial. Epilepsia. 2000;41(s1):86-90.

48. French JA, Kanner AM, Bautista J, Abou-Khalil B, Browne T, Harden CL, et al. Efficacy and tolerability of the new antiepileptic drugs II: treatment of refractory epilepsy: report of the Therapeutics and Technology Assessment Subcommittee and Quality Standards Subcommittee of the American Academy of Neurology and the American Epile. Neurology. 2004;62(8):1261-73.

49. Moavero R, Santarone ME, Galasso C, Curatolo P. Cognitive and behavioral effects of new antiepileptic drugs in pediatric epilepsy. Brain Dev. 2017;39(6):464-9.

50. Bootsma HP, Ricker L, Hekster YA, Hulsman J, Lambrechts D, Majoie M, et al. The impact of side effects on long-term retention in three new antiepileptic drugs. Seizure. 2009;18(5):327-31.

51. Borrelli S, El Tahry R. Therapeutic approach to LennoxGastaut syndrome: a systematic review. Acta Neurol Belg. 2019;119(3):315-24.

52. Swinyard EA, Sofia RD, Kupferberg HJ. Comparative anticonvulsant activity and neurotoxicity of felbamate and four prototype antiepileptic drugs in mice and rats. Epilepsia. 1986;27(1):27-34.

53. The Felbamate Study Group in Lennox-Gastaut Syndrome. Efficacy of felbamate in childhood epileptic encephalopathy (Lennox-Gastaut Syndrome). N Engl J Med. 1993;328(1):29-33.

54. Pellock JM. Felbamate. Epilepsia. 1999;40(s5):s57-62.

55. Dodson WE. Felbamate in the treatment of Lennox-Gastaut Syndrome: results of a 12-month open-label Study following a randomized clinical trial. Epilepsia. 1993;34(s7):S18-24.

56. Thakkar K, Billa G, Rane J, Chudasama H, Goswami S, Shah $\mathrm{R}$. The rise and fall of felbamate as a treatment for partial epilepsy-aplastic anemia and hepatic failure to blame? Expert Rev Neurother. 2015;15(12):1373-5.

57. Heyman E, Levin N, Lahat E, Epstein O, Gandelman-Marton R. Efficacy and safety of felbamate in children with refractory epilepsy. Eur J Paediatr Neurol. 2014;18(6):658-62.

58. Shah YD, Singh K, Friedman D, Devinsky O, Kothare SV. Evaluating the safety and efficacy of felbamate in the context of a black box warning: a single center experience. Epilepsy Behav. 2016;56:50-3.

59. Zupanc ML, Roell Werner R, Schwabe MS, O'Connor SE, Marcuccilli CJ, Hecox KE, et al. Efficacy of felbamate in the treatment of intractable pediatric epilepsy. Pediatr Neurol. 2010;42(6):396-403.

60. Song JM, Hahn J, Kim SH, Chang MJ. Efficacy of treatments for infantile spasms: a systematic review. Clin Neuropharmacol. 2017;40(2):63-84.

61. Mehta V, Ferrie CD, Cross JH, Vadlamani G. Corticosteroids including ACTH for childhood epilepsy other than epileptic spasms. Cochrane Database Syst Rev. 2015;(6):CD005222.

62. Bast T, Richter S, Ebinger F, Rating D, Wiemer-Kruel A, Schubert-Bast S. Efficacy and tolerability of methylprednisolone pulse therapy in childhood epilepsies other than infantile spasms. Neuropediatrics. 2014;45(6):378-85.

63. Bakker DP, Catsman-Berrevoets CE, Neuteboom RF. Effectiveness of a hybrid corticosteroid treatment regimen on refractory childhood seizures and a review of other corticosteroid treatments. Eur J Paediatr Neurol. 2015;19(5):553-60.

64. Wheless JW, Vazquez B. Rufinamide: a novel broad-spectrum antiepileptic drug. Epilepsy Curr. 2010;10(1):1-6.

65. BANZEL. Prescribing information. https://www.accessdata.fda. gov/drugsatfda_docs/label/2015/021911s012lbl.pdf. Accessed 22 July 2020.
66. INOVELON. Summary of product characteristcs. https://www. ema.europa.eu/en/documents/product-information/inovelonepar-product-information_en.pdf. Accessed 22 July 2020.

67. Glauser T, Kluger G, Sachdeo R, Krauss G, Perdomo C, Arroyo S. Rufinamide for generalized seizures associated with Lennox-Gastaut syndrome. Neurology. 2008;70(21):1950-8.

68. Arzimanoglou A, Ferreira J, Satlin A, Olhaye O, Kumar D, Dhadda S, et al. Evaluation of long-term safety, tolerability, and behavioral outcomes with adjunctive rufinamide in pediatric patients ( $\geq 1$ to $<4$ years old) with Lennox-Gastaut syndrome: final results from randomized study 303 . Eur J Paediatr Neurol. 2019;23(1):126-35.

69. Arzimanoglou A, Ferreira JA, Satlin A, Mendes S, Williams B, Critchley D, et al. Safety and pharmacokinetic profile of rufinamide in pediatric patients aged less than 4 years with Lennox-Gastaut syndrome: an interim analysis from a multicenter, randomized, active-controlled, open-label study. Eur J Paediatr Neurol. 2016;20(3):393-402.

70. Kluger G, Glauser T, Krauss G, Seeruthun R, Perdomo C, Arroyo S. Adjunctive rufinamide in Lennox-Gastaut syndrome: a long-term, open-label extension study. Acta Neurol Scand. 2010;122(3):202-8.

71. Ohtsuka Y, Yoshinaga H, Shirasaka Y, Takayama R, Takano H, Iyoda K. Rufinamide as an adjunctive therapy for Lennox-Gastaut syndrome: a randomized double-blind placebo-controlled trial in Japan. Epilepsy Res. 2014;108(9):1627-36.

72. Auvin S, Williams B, McMurray R, Kumar D, Perdomo C, Malhotra M. Novel seizure outcomes in patients with LennoxGastaut syndrome: Post hoc analysis of seizure-free days in rufinamide study 303. Epilepsia Open. 2019;4(2):275-80.

73. Ohtsuka Y, Yoshinaga H, Shirasaka Y, Takayama R, Takano $\mathrm{H}$, Iyoda K. Long-term safety and seizure outcome in Japanese patients with Lennox-Gastaut syndrome receiving adjunctive rufinamide therapy: An open-label study following a randomized clinical trial. Epilepsy Res. 2016;121:1-7.

74. Coppola G, Grosso S, Franzoni E, Veggiotti P, Zamponi N, Parisi P, et al. Rufinamide in children and adults with LennoxGastaut syndrome: First Italian multicenter experience. Seizure. 2010;19(9):587-91.

75. Kim SH, Eun SH, Kang HC, Kwon EJ, Byeon JH, Lee YM, et al. Rufinamide as an adjuvant treatment in children with Lennox-Gastaut syndrome. Seizure. 2012;21(4):288-91.

76. Kim SH, Kang HC, Lee JS, Kim HD. Rufinamide efficacy and safety in children aged 1-4 years with Lennox-Gastaut syndrome. Brain Dev. 2018;40(10):897-903.

77. Kluger G, Haberlandt E, Kurlemann G, Ernst JP, Runge U, Schneider F, et al. First European long-term experience with the orphan drug rufinamide in childhood-onset refractory epilepsy. Epilepsy Behav. 2010;17(4):546-8.

78. Lee EH, Yum MS, Ko TS. Effectiveness and tolerability of rufinamide in children and young adults with Lennox-Gastaut syndrome: a single center study in Korea. Clin Neurol Neurosurg. 2013;115(7):926-9.

79. Nikanorova M, Brandt C, Auvin S, McMurray R. Real-world data on rufinamide treatment in patients with Lennox-Gastaut syndrome: Results from a European noninterventional registry study. Epilepsy Behav. 2017;76:63-70.

80. Balagura G, Riva A, Marchese F, Verrotti A, Striano P. Adjunctive rufinamide in children with Lennox-Gastaut syndrome: a literature review. Neuropsychiatr Dis Treat. 2020;16:369-79.

81. Striano P, McMurray R, Santamarina E, Falip M. Rufinamide for the treatment of Lennox-Gastaut syndrome: evidence from clinical trials and clinical practice. Epileptic Disord. 2018;20(1):13-29.

82. Gray RA, Whalley BJ. The proposed mechanisms of action of CBD in epilepsy. Epileptic Disord. 2020;22(S1):10-5. 
83. European Medicines Agency. Epidyolex. https://www.ema.europ a.eu/en/medicines/human/EPAR/epidyolex Accessed Mar 2020.

84. Devinsky O, Cross JH, Laux L, Marsh E, Miller I, Nabbout R, et al. Trial of cannabidiol for drug-resistant seizures in the Dravet syndrome. N Engl J Med. 2017;376(21):2011-20.

85. EPIDIOLEX. Prescribing Information. https://www.accessdata .fda.gov/drugsatfda_docs/label/2018/210365lbl.pdf Accessed Mar 2020.

86. Devinsky O, Patel AD, Cross JH, Villanueva V, Wirrell EC, Privitera $\mathrm{M}$, et al. Effect of cannabidiol on drop seizures in the Lennox-Gastaut syndrome. N Engl J Med. 2018;378(20):1888-97.

87. Thiele EA, Marsh ED, French JA, Mazurkiewicz-Beldzinska M, Benbadis SR, Joshi C, et al. Cannabidiol in patients with seizures associated with Lennox-Gastaut syndrome (GWPCARE4): a randomised, double-blind, placebo-controlled phase 3 trial. Lancet. 2018;391(10125):1085-96.

88. Thiele E, Marsh E, Mazurkiewicz-Beldzinska M, Halford JJ, Gunning B, Devinsky O, et al. Cannabidiol in patients with Lennox-Gastaut syndrome: Interim analysis of an open-label extension study. Epilepsia. 2019;60(3):419-28.

89. Laux LC, Bebin EM, Checketts D, Chez M, Flamini R, Marsh $\mathrm{ED}$, et al. Long-term safety and efficacy of cannabidiol in children and adults with treatment resistant Lennox-Gastaut syndrome or Dravet syndrome: Expanded access program results. Epilepsy Res. 2019;154:13-20.

90. Bialer M, Perucca E. Does cannabidiol have antiseizure activity independent of its interactions with clobazam? An appraisal of the evidence from randomized controlled trials. Epilepsia. 2020;61(6):1082-9.

91. Lattanzi S, Brigo F, Trinka E, Zaccara G, Striano P, Del Giovane $\mathrm{C}$, et al. Adjunctive cannabidiol in patients with dravet syndrome: a systematic review and meta-analysis of efficacy and safety. CNS Drugs. 2020;34(3):229-41.

92. Lattanzi S, Trinka E, Striano P, Zaccara G, Del Giovane C, Nardone R, et al. Cannabidiol efficacy and clobazam status: a systematic review and meta-analysis. Epilepsia. 2020;61(6):1090-8.

93. Klotz KA, Hirsch M, Heers M, Schulze-Bonhage A, Jacobs J. Effects of cannabidiol on brivaracetam plasma levels. Epilepsia. 2019;60(7):e74-7.

94. Gaston TE, Bebin EM, Cutter GR, Liu Y, Szaflarski JP. Interactions between cannabidiol and commonly used antiepileptic drugs. Epilepsia. 2017;58(9):1586-92.

95. Klein P, Tolbert D, Gidal BE. Drug-drug interactions and pharmacodynamics of concomitant clobazam and cannabidiol or stiripentol in refractory seizures. Epilepsy Behav. 2019;99:106459.

96. Grayson L, Vines B, Nichol K, Szaflarski JP. An interaction between warfarin and cannabidiol, a case report. Epilepsy Behav Case Rep. 2018;9:10-1.

97. Polster T. Individualized treatment approaches: Fenfluramine, a novel antiepileptic medication for the treatment of seizures in Dravet syndrome. Epilepsy Behav. 2019;91:99-102.

98. FINTEPLA. Prescribing Information. https://www.accessdata .fda.gov/drugsatfda_docs/label/2020/212102s000lbl.pdf. Accessed July 2020.

99. Lagae L, Schoonjans AS, Gammaitoni AR, Galer BS, Ceulemans B. A pilot, open-label study of the effectiveness and tolerability of low-dose ZX008 (fenfluramine $\mathrm{HCl}$ ) in Lennox-Gastaut syndrome. Epilepsia. 2018;59(10):1881-8.

100. Sourbron J, Smolders I, de Witte P, Lagae L. Pharmacological Analysis of the anti-epileptic mechanisms of fenfluramine in scn1a mutant zebrafish. Front Pharmacol. 2017;8:191.

101. Martin P, de Witte PAM, Maurice T, Gammaitoni A, Farfel G, Galer B. Fenfluramine acts as a positive modulator of sigma-1 receptors. Epilepsy Behav. 2020;105:106989.
102. Connolly HM, Crary JL, McGoon MD, Hensrud DD, Edwards BS, Edwards WD, et al. Valvular heart disease associated with fenfluramine-phentermine. N Engl J Med. 1997;337(9):581-8.

103. Lai WW, Pringsheim M, Farfel G, Galer BS, Morrison G, Gammaitoni A, et al. Long-term cardiovascular safety of fenfluramine HCL (Fintepla ${ }^{\circledR}$ ) in the treatment of Dravet syndrome: Interim analysis of an open-label safety extension study. 72nd American Epilepsy Society Annual Meeting, December 2018. Abst. 3.453. 2018. https://www.aesnet.org/meetings_events/annual_meeting_ abstracts/view/554593 and https://www.zogenix.com/wp-conte nt/uploads/2018/12/3.453_AES_Study-1503-Long-Term-CV.pdf. Accessed Mar 2020.

104. Schoonjans AS, Marchau F, Paelinck BP, Lagae L, Gammaitoni A, Pringsheim M, et al. Cardiovascular safety of lowdose fenfluramine in Dravet syndrome: a review of its benefitrisk profile in a new patient population. Curr Med Res Opin. 2017;33(10):1773-81.

105. Zogenix. Zogenix announces positive top-line results from global pivotal phase 3 trial of FINTEPLA ${ }^{\circledR}$ for the treatment of LennoxGastaut syndrome. 2020. https://zogenixinc.gcs-web.com/newsreleases/news-release-details/zogenix-announces-positive-topline-results-global-pivotal-phase. Accessed 15 July 2020.

106. Strzelczyk A, Schubert-Bast S. Therapeutic advances in Dravet syndrome: a targeted literature review. Expert Rev Neurother 2020;20:1065-79.

107. Boyd B, Smith S, Gammaitoni A, Galer BS, Farfel GM. A phase I, randomized, open-label, single-dose, 3-period crossover study to evaluate the drug-drug interaction between ZX008 (fenfluramine $\mathrm{HCl}$ oral solution) and a regimen of stiripentol, clobazam, and valproate in healthy subjects. Int J Clin Pharmacol Ther. 2019;57(1):11-9.

108. Boyd B, Smith S, Farfel GM, Morrison G. A phase 1, singledose, open-label pharmacokinetic study to investigate the drugdrug interaction potential of ZX008 (Fenfluramine HCl Oral Solution) and Cannabidiol. 73rd American Epilepsy Society Annual Meeting, December 2019. https://www.zogenix.com/ wp-content/uploads/2019/12/10_ENCORE-52370-AES-1604CBD-Poster-2019-12-03v1.pdf. Accessed Apr 2020.

109. Schubert-Bast S, Wolff M, Wiemer-Kruel A, von Spiczak S, Trollmann R, Reif PS, et al. Seizure management and prescription patterns of anticonvulsants in Dravet syndrome: A multicenter cohort study from Germany and review of literature. Epilepsy Behav. 2019;98:88-95.

110. FYCOMPA. Prescribing information. https://www.accessdata .fda.gov/drugsatfda_docs/label/2016/202834s0111bl.pdf. Accessed 15 July 2020.

111. FYCOMPA. Summary of product characteristcs. https://www. ema.europa.eu/en/documents/product-information/fycompaepar-product-information_en.pdf. Accessed 15 July 2020.

112. Clinicaltrials.gov. NCT02834793: study of perampanel as adjunctive treatment for inadequately controlled seizures associated with Lennox-Gastaut syndrome. https://clinicaltrials.gov/ ct $2 /$ show/NCT02834793. Accessed 15 July 2020.

113. Crespel A, Tang NPL, Macorig G, Gelisse P, Genton P. Openlabel, uncontrolled retrospective study of perampanel in adults with Lennox-Gastaut syndrome. Seizure. 2020;75:66-9.

114. Biró A, Stephani U, Tarallo T, Bast T, Schlachter K, Fleger M, et al. Effectiveness and tolerability of perampanel in children and adolescents with refractory epilepsies: first experiences. Neuropediatrics. 2015;46(2):110-6.

115. Huber B, Schmid G. A two-year retrospective evaluation of perampanel in patients with highly drug-resistant epilepsy and cognitive impairment. Epilepsy Behav. 2017;66:74-9.

116. Steinhoff BJ, Bacher M, Bast T, Kornmeier R, Kurth C, Scholly J, et al. First clinical experiences with perampanel-the Kork experience in 74 patients. Epilepsia. 2014;55(Suppl 1):16-8. 
117. Auvin S, Dozieres B, Ilea A, Delanoë C. Use of perampanel in children and adolescents with Lennox-Gastaut syndrome. Epilepsy Behav. 2017;74:59-63.

118. Rohracher A, Zimmermann G, Villanueva V, Garamendi I, Sander JW, Wehner T, et al. Perampanel in routine clinical use across Europe: pooled, multicenter, observational data. Epilepsia. 2018;59(9):1727-39.

119. Strzelczyk A, Willems LM, Willig S, Rosenow F, Bauer S. Perampanel in the treatment of focal and idiopathic generalized epilepsies and of status epilepticus. Expert Rev Clin Pharmacol. 2015;8(6):733-40.

120. You SJ, Kang HC, Kim HD, Lee HS, Ko TS. Clinical efficacy of zonisamide in Lennox-Gastaut syndrome: Korean multicentric experience. Brain Dev. 2008;30(4):287-90.

121. Kim HJ, Kim SH, Kang H-C, Lee JS, Chung HJ, Kim HD. Adjunctive levetiracetam treatment in pediatric Lennox-Gastaut syndrome. Pediatr Neurol. 2014;51(4):527-31.

122. KEPPRA. Summary of product characteristics. https://www. medicines.org.uk/emc/product/2293/smpc\#gref. Accessed Aug 2020.

123. Nissenkorn A, Tzadok M, Bar-Yosef O, Ben-Zeev B. Treatment with brivaracetam in children - The experience of a pediatric epilepsy center. Epilepsy Behav. 2019;101(Pt A):106541.

124. Villanueva V, López-González FJ, Mauri JA, RodriguezUranga J, Olivé-Gadea M, Montoya J, et al. BRIVA-LIFEA multicenter retrospective study of the long-term use of brivaracetam in clinical practice. Acta Neurol Scand. 2019;139(4):360-8.

125. Willems LM, Bertsche A, Bösebeck F, Hornemann F, Immisch I, Klein KM, et al. Efficacy, retention, and tolerability of brivaracetam in patients with epileptic encephalopathies: a multicenter cohort study From Germany. Front Neurol. 2018;9:569.

126. Willems LM, Bauer S, Rosenow F, Strzelczyk A. Recent advances in the pharmacotherapy of epilepsy: brivaracetam and perampanel as broad-spectrum antiseizure drugs for the treatment of epilepsies and status epilepticus. Expert Opin Pharmacother. 2019;20(14):1755-65.

127. Steinig I, von Podewils F, Möddel G, Bauer S, Klein KM, Paule E, et al. Postmarketing experience with brivaracetam in the treatment of epilepsies: A multicenter cohort study from Germany. Epilepsia. 2017;58(7):1208-16.

128. Halford J, Arkilo D, Asgharnejad M, Zinger C, Chen S, During $\mathrm{M}$, et al. Initial data from the ongoing ENDYMION open-label extension trial of soticlestat (TAK-935/OV935) in participants with developmental and/or epileptic encephalopathies (DEE) (4492). Neurology. 2020;94(15 Supplement):4492.

129. Ghasemi M, Schachter SC. The NMDA receptor complex as a therapeutic target in epilepsy: a review. Epilepsy Behav. 2011;22(4):617-40.

130. Steriade C, French J, Devinsky O. Epilepsy: key experimental therapeutics in early clinical development. Expert Opin Investig Drugs. 2020;29(4):373-83.

131. ClinicalTrials.gov NCT03650452. A phase 2, multicenter, randomized, double-blind, placebo-controlled study to evaluate the efficacy, safety, and tolerability of TAK-935 (OV935) as an adjunctive therapy in pediatric patients with developmental and/ or Epileptic Encephalopathies (ELEKTRA). https://clinicaltrials. gov/ct2/show/NCT03650452. Accessed Mar 2020.

132. Ovid Therapeutics. Phase 2 ELEKTRA trial positive topline results. 2020. https://investors.ovidrx.com/static-files/a75b1 d83-5b5d-47d2-bc9f-039e8fe78154. Accessed Aug 2020.

133. ClinicalTrials.gov. NCT03635073. A phase 2, prospective, interventional, open-label, multi-site, extension study to assess the long-term safety and tolerability of TAK-935 (OV935) as adjunctive therapy in patients with rare Epilepsy (Endymion). https:// clinicaltrials.gov/ct2/show/NCT03635073 Accessed Mar 2020.
134. Halford J, Sperling M, Arkilo D, Asgharnejad M, Zinger C, Xu $\mathrm{R}$, et al. A phase 1b/2a study of soticlestat (TAK-935/OV935) as adjunctive therapy in adults with developmental and/or epileptic encephalopathies (DEE) (4715). Neurology. 2020;94(15 Supplement):4715.

135. Clinicaltrials.gov. NCT03731715: Carisbamate in adult \& pediatric subjects with Lennox-Gastaut syndrome. https://clini caltrials.gov/ct2/show/NCT03731715. Accessed 15 July 2020.

136. Hadera MG, Faure J-B, Berggaard N, Tefera TW, Nehlig A, Sonnewald U. The anticonvulsant actions of carisbamate associate with alterations in astrocyte glutamine metabolism in the lithium-pilocarpine epilepsy model. J Neurochem. 2015;132(5):532-45.

137. Ghosh AK, Brindisi M. Organic carbamates in drug design and medicinal chemistry. J Med Chem. 2015;58(7):2895-940.

138. Strzelczyk A, Mann C, Willems LM, Rosenow F, Bauer S. Cenobamate for the treatment of focal epilepsies. Expert Opin Pharmacother. 2020;21(18):2215-23.

139. Devinsky O, Segal E, Chez M, Waksman J, Lappalainen J, Masuoka L. Open-label trial of ganaxolone in children with Lennox-Gastaut syndrome. American Epilepsy Society (Abstract 3.427). 2017. https://www.aesnet.org/meetings_event s/annual_meeting_abstracts/view/392831. Accessed 15 July 2020.

140. Marinus Pharmaceuticals. Pipeline: clinical trial information. https://www.marinuspharma.com/our-science-pipeline/ourpipeline. Accessed 15 July 2020.

141. Winesett SP, Bessone SK, Kossoff EH. The ketogenic diet in pharmacoresistant childhood epilepsy. Expert Rev Neurother. 2015;15(6):621-8.

142. Simeone TA, Simeone KA, Rho JM. Ketone bodies as antiseizure agents. Neurochem Res. 2017;42(7):2011-8.

143. Rogawski MA, Löscher W, Rho JM. Mechanisms of action of antiseizure drugs and the ketogenic diet. Cold Spring Harb Perspect Med. 2016;6(5):a022780.

144. Martin-McGill KJ, Jackson CF, Bresnahan R, Levy RG, Cooper PN. Ketogenic diets for drug-resistant epilepsy. Cochrane Database Syst Rev. 2018;11(11);CD001903.

145. Liu H, Yang Y, Wang Y, Tang H, Zhang F, Zhang Y, et al. Ketogenic diet for treatment of intractable epilepsy in adults: a meta-analysis of observational studies. Epilepsia Open. 2018;3(1):9-17.

146. Lyons L, Schoeler NE, Langan D, Cross JH. Use of ketogenic diet therapy in infants with epilepsy: a systematic review and meta-analysis. Epilepsia. 2020;61(6):1261-81.

147. Caraballo RH, Fortini S, Fresler S, Armeno M, Ariela A, Cresta A, et al. Ketogenic diet in patients with Lennox-Gastaut syndrome. Seizure. 2014;23(9):751-5.

148. Lemmon ME, Terao NN, Ng YT, Reisig W, Rubenstein JE, Kossoff EH. Efficacy of the ketogenic diet in Lennox-Gastaut syndrome: a retrospective review of one institution's experience and summary of the literature. Dev Med Child Neurol. 2012;54(5):464-8.

149. Zhang Y, Wang Y, Zhou Y, Zhang L, Yu L, Zhou S. Therapeutic effects of the ketogenic diet in children with LennoxGastaut syndrome. Epilepsy Res. 2016;128:176-80.

150. Sharma S, Jain P, Gulati S, Sankhyan N, Agarwala A. Use of the modified atkins diet in Lennox Gastaut syndrome. J Child Neurol. 2015;30(5):576-9.

151. van Berkel AA, DM IJ, Verkuyl JM. Cognitive benefits of the ketogenic diet in patients with epilepsy: a systematic overview. Epilepsy Behav. 2018;87:69-77.

152. Williams TJ, Cervenka MC. The role for ketogenic diets in epilepsy and status epilepticus in adults. Clin Neurophysiol Pract. 2017;2:154-60. 
153. Ye F, Li X-J, Jiang W-L, Sun H-B, Liu J. Efficacy of and patient compliance with a ketogenic diet in adults with intractable epilepsy: a meta-analysis. J Clin Neurol. 2015;11(1):26-31.

154. Morris GL, Gloss D, Buchhalter J, Mack KJ, Nickels K, Harden C. Evidence-based guideline update: vagus nerve stimulation for the treatment of epilepsy. Rep Guidel Dev Subcomm Am Acad Neurol. 2013;81(16):1453-9.

155. Lancman G, Virk M, Shao H, Mazumdar M, Greenfield JP, Weinstein S, et al. Vagus nerve stimulation vs. corpus callosotomy in the treatment of Lennox-Gastaut syndrome: a meta-analysis. Seizure. 2013;22(1):3-8.

156. Cukiert A, Cukiert CM, Burattini JA, Lima AM, Forster CR, Baise $\mathrm{C}$, et al. Long-term outcome after callosotomy or vagus nerve stimulation in consecutive prospective cohorts of children with Lennox-Gastaut or Lennox-like syndrome and non-specific MRI findings. Seizure. 2013;22(5):396-400.

157. Rolston JD, Englot DJ, Wang DD, Garcia PA, Chang EF. Corpus callosotomy versus vagus nerve stimulation for atonic seizures and drop attacks: a systematic review. Epilepsy Behav. 2015;51:13-7.

158. Smyth MD, Vellimana AK, Asano E, Sood S. Corpus callosotomy-open and endoscopic surgical techniques. Epilepsia. 2017;58(Suppl 1):73-9.

159. Ball T, Sharma M, White AC, Neimat JS. Anterior corpus callosotomy using laser interstitial thermal therapy for refractory epilepsy. Stereotact Funct Neurosurg. 2018;96(6):406-11.

160. Ho AL, Miller KJ, Cartmell S, Inoyama K, Fisher RS, Halpern $\mathrm{CH}$. Stereotactic laser ablation of the splenium for intractable epilepsy. Epilepsy Behav Case Rep. 2016;5:23-6.

161. Huang Y, Yecies D, Bruckert L, Parker JJ, Ho AL, Kim LH, et al. Stereotactic laser ablation for completion corpus callosotomy. J Neurosurg Pediatr. 2019. https://doi.org/10.3171/2019.5.PEDS1 9117.

162. Karsy M, Patel DM, Halvorson K, Mortimer V, Bollo RJ. Anterior two-thirds corpus callosotomy via stereotactic laser ablation. Neurosurg Focus. 2018;44(VideoSuppl2):V2.

163. Lehner KR, Yeagle EM, Argyelan M, Klimaj Z, Du V, Megevand $\mathrm{P}$, et al. Validation of corpus callosotomy after laser interstitial thermal therapy: a multimodal approach. J Neurosurg. 2019;131:1095-105.

164. Palma AE, Wicks RT, Popli G, Couture DE. Corpus callosotomy via laser interstitial thermal therapy: a case series. J Neurosurg Pediatr. 2018;23(3):303-7.

165. Roland JL, Akbari SHA, Salehi A, Smyth MD. Corpus callosotomy performed with laser interstitial thermal therapy. J Neurosurg. 2019;1:1-9. https://doi.org/10.3171/2019.9.JNS191769

166. Tao JX, Issa NP, Wu S, Rose S, Collins J, Warnke PC. Interstitial stereotactic laser anterior corpus callosotomy: a report of 2 cases with operative technique and effectiveness. Neurosurgery. 2019;85(3):E569-74

167. Tao JX, Satzer D, Issa NP, Collins J, Wu S, Rose S, et al. Stereotactic laser anterior corpus callosotomy for Lennox-Gastaut syndrome. Epilepsia. 2020;61(6):1190-200.

168. Zöllner JP, Franz DN, Hertzberg C, Nabbout R, Rosenow F, Sauter M, et al. A systematic review on the burden of illness in individuals with tuberous sclerosis complex (TSC). Orphanet J Rare Dis. 2020;15(1):23.

169. Kang JW, Eom S, Hong W, Kwon HE, Park S, Ko A, et al. Longterm outcome of resective epilepsy surgery in patients with Lennox-Gastaut Syndrome. Pediatrics. 2018;142(4):e20180449.

170. Hancock EC, Cross JH. Treatment of Lennox-Gastaut syndrome. Cochrane Database of Syst Rev. 2013;(2):CD003277.

171. Germain N, Aballéa S, Toumi M. Measuring the health-related quality of life in young children: how far have we come? J Mark Access Health Policy. 2019;7(1):1618661.

172. Cohen JS, Biesecker BB. Quality of life in rare genetic conditions: a systematic review of the literature. Am J Med Genet A. 2010;152(5):1136-56.

173. Bishop KI, Isquith PK, Gioia G, Morrison G, Gammaitoni AR, Haney D, et al. Profound reduction in seizure frequency $(\geq 75 \%)$ leads to improved everyday executive function: Analysis from a phase 3 study of ZX008 (fenfluramine HCL) in children/young adults with Dravet syndrome. 73rd American Epilepsy Society Annual Meeting, December 2019. Abst. 2.438. 2019. https:// www.aesnet.org/meetings_events/annual_meeting_abstracts/ view/2421880 and https://www.zogenix.com/wp-content/uploa ds/2019/12/01.-FINAL-52349-AES-BRIEF-Poster-2019-1203v4.pdf Accessed Mar 2020.

174. Lagae L, Sullivan J, Knupp K, Laux L, Polster T, Nikanorova M, et al. Fenfluramine hydrochloride for the treatment of seizures in Dravet syndrome: a randomised, double-blind, placebo-controlled trial. Lancet. 2020;394(10216):2243-54.

175. Bishop KI, Gioia G, Isquith PK, Gammaitoni A, Farfel G, Galer BS, et al. Improved everyday executive function with fenfluramine HCL oral solution (Fintepla®): Results from a phase 3 study in children and young adults with Dravet syndrome. 72nd American Epilepsy Society Annual Meeting, December 2018. Abst. 2.454. https://www.aesnet.org/meetings_events/annual_ meeting_abstracts/view/552618 and https://www.zogenix.com/ wp-content/uploads/2018/11/2.454-AES-Study-1-BRIEF.pdf Accessed Mar 2020.

176. Operto FF, Verrotti A, Marrelli A, Ciuffini R, Coppola G, Pastorino GMG, et al. Cognitive, adaptive, and behavioral effects of adjunctive rufinamide in Lennox-Gastaut syndrome: a prospective observational clinical study. Epilepsy Behav. 2020;112:107445. 